\title{
San Isidro, de labrador medieval a patrón renacentista y barroco de la Villa y Corte $^{1}$
}

\author{
MATILDE FERNÁNDEZ MONTES \\ Departamento de Antropología de España y América \\ CSIC, Madrid
}

Un SANTO LOCAL EN LA CASTILLA DEL SIGLO XIII. LOS MILAgros PÓSTUMOS DEL CÓDICE

No deja de ser sorprendente que Madrid, uno de los grandes núcleos urbanos peninsulares, tenga su principal advocación dentro del santoral en un labrador, con muchos de sus milagros vinculados al mundo agrícola, hasta el punto de considerársele también el patrón de todos los campesinos, contando con una amplia gama de manifestaciones de culto, dentro del ámbito rural. Para comprenderlo es necesario retroceder al momento en que se empezó a venerar y seguir las evoluciones paralelas de las personalidades de la villa y su santo.

Si nos fiamos de las fechas contenidas en el llamado Códice de Juan Diácono (Anónimo 1993: 124), el culto a San Isidro se inició a finales del siglo XII, al identificarse un cuerpo incorrupto hallado en el cementerio de la iglesia de San Andrés, con un madrileño legendario que había fallecido cuarenta años antes y al que, de manera unánime, el pueblo y los caballeros comienzan a invocar como santo, convencidos por los prodigios acontecidos durante la traslación del cadáver (Fernández Montes 1999: 50). Este es descubierto en un momento muy oportuno, ya que, aunque desde 1083, cuando Toledo fue tomado por Alfonso VI, Madrid había estado bajo el dominio cristiano en repetidas ocasiones, no se puede hablar de verdadera cristianización del territorio hasta 1162, al ocupar Fernando II definitivamente la ciudad. Con su aparición, se soluciona el problema de las reliquias que eran necesarias para la consagración de las iglesias. Las de santos ya canonizados o de cierto renombre con un culto

${ }^{1}$ El presente estudio ha sido realizado dentro del proyecto de investigación PB 97-1182, Análisis antropológico de las manifestaciones de culto a santos y vírgenes en Madrid. Se trata de la continuación de un artículo anteriormente publicado: "Isidro el varón de Dios como modelo de sincretismo religioso en la Edad Median, (Fernández Montes 1999: 7-51) cuya lectura previa resulta aconsejable. 
geográficamente extenso, rara vez dejaron de ser cuestionadas, además de las interminables disputas entre varias ciudades y órdenes religiosas, pero al tener los restos completos de un sólo individuo que desarrolló toda su vida en Madrid, éste se convierte en un santo local indiscutible, sin exponerse a las reivindicaciones de otras poblaciones, ni a la multiplicación y duplicación de sus reliquias. Por otra parte, la humilde villa madrileña tampoco hubiera podido aspirar a mucho más.

La verdadera vida de los santos empieza después de su muerte, cuando, reconocida su condición, se inicia el culto. El culto a los santos de carácter popular hace revivir a los muertos, infunde vida a la leyenda y proporciona patronos a cada comunidad cristiana (Delehaye 1962). La prueba genuina de su santidad radica en los milagros póstumos ${ }^{2}$ que se producen a través de su mediación. Mientras la Iglesia prefiere al erudito modelo de virtudes como Santo Tomás de Aquino, el pueblo demanda el santo taumaturgo que frecuentemente, como en el caso que nos ocupa, no se intentará tan siquiera que sea canonizado por el papa, siendo suficiente la aprobación del obispo local para el reconocimiento de esta condición.

En el Códice con la vida del patrón de Madrid, fechado en el último tercio del siglo XIII, se pueden establecer dos grandes bloques según la cronología de su contenido. El primero, conocido como "La leyenda de San Isidro", contiene el relato de cinco milagros acaecidos durante la vida del personaje, es decir en el siglo XII. A su análisis dediqué un amplio artículo (Fernández Montes 1999) mostrando el carácter sincrético y conciliador del personaje en el que, con facilidad, se rastrea una mezcla de los modelos de santidad islámica y cristiana que sin duda estuvieron vigentes en Madrid, durante la doceava centuria. En repetidas ocasiones aludiremos a estos prodigios, aunque ahora lo que nos interesa es el segundo bloque donde aparecen dos series de milagros, acaecidos gracias a la invocación y culto al cuerpo incorrupto y separados entre sí por seis himnos que se cantaban en los oficios en su honor dentro de la iglesia de San Andrés. Estos episodios en más de una ocasión están fechados, siendo la cronología más temprana 1212 y la última 1275 , lo que se ajusta con bastante precisión a la caligrafía del documento, datada en el último tercio del siglo XIII.

Frente a la imprecisión que envuelve la leyenda de San Isidro, los milagros póstumos aportan toda una serie de datos, nombres y fechas que pretenden avalar y certificar lo relatado y nos ayudan a comprender no sólo las manifestaciones de culto en el siglo xiII, sino también detalles de

\footnotetext{
${ }^{2}$ Este aserto es especialmente aplicable a los santos patronos, pues no se exige de igual manera a los mártires o ascetas.
} 
las principales demandas y necesidades del Madrid medieval, además de algunos aspectos de la religiosidad en este siglo. Los anteriores a los himnos, de mayor precisión cronológica y onomástica, suceden durante los reinados de Fernando II y Alfonso VIII, diferenciándose también de los de la segunda por su mayor amplitud.

La principal característica común de ambas series es su total distanciamiento de las narraciones contenidas en la leyenda inicial que transcurre cuando el santo estaba vivo en el siglo xII, mostrándonos cómo el personaje ya ha comenzado a evolucionar, ajustándose a las demandas de una sociedad que ha transformado sus patrones culturales. A grandes rasgos, se podrían dividir en tres grupos temáticos: milagros realizados con objeto de afianzar el culto, milagros hidráulicos, en general concesión de lluvias tras rogativas y por último, curaciones milagrosas.

Para obtener la mediación del santo es necesario rendirle culto acudiendo a orar ante su sepulcro, preferentemente en vigilias nocturnas que se prolongan una, tres o nueve noches. En caso de enfermedad el afectado tiene que ir (o ser llevado) personalmente, no pudiendo ser sustituido por sus familiares. El contacto con el sudario o con el cadáver suele ser decisivo para obtener la mediación, al igual que, cuando se demanda lluvia, para facilitarla se opta por abrir el sepulcro y colocar el cadáver en un pedestal frente al altar de San Andrés con el fin de que ningún objeto pueda dificultar la comunicación entre el santo y Dios. También para posibilitar la mediación se realizan numerosas procesiones y rogativas, durante las cuales, al sacar la reliquia de su recinto sagrado y exponerla al aire libre, se favorece la intercesión.

La extensión y arraigo del culto a San Isidro es el motivo más frecuente que provoca los llamados "milagros-castigo" que recaen en personas que dudan, se mofan o incumplen promesas, como sucedió en el caso narrado en el artículo anterior (Fernández Montes 1999: 49-50), en el que un individuo cayó enfermo tras dudar de una aparición nocturna del santo que solicitaba al visionario el traslado de su cuerpo, desde el cementerio al interior de la iglesia de San Andrés.

También el celo por preservar y aumentar el culto es el tema del episodio narrado bajo el epígrafe 15 (Anónimo 1993: 126) en el que se cuenta cómo en "la sequía más grave del tiempo de peste", un moro hizo el voto de convertirse al cristianismo si se obtenían las lluvias pedidas, diciendo que si, concedida la súplica, él no cumplía su promesa, muriera de una mala muerte ${ }^{3}$. Ante el incumplimiento del voto, el moro "pereció

\footnotetext{
${ }^{3}$ Se consideraba, tanto por moros como por cristianos, "una mala muerten el fallecimiento súbito, sin disponer de tiempo para prepararse y quedar en paz con Dios y los hombres, lo que implicaría no tener garantizado el acceso a la gloria eterna.
} 
de una mala muerte apuñalado por un matamoros". Destacamos este milagro porque nos muestra cómo Isidro era venerado y rogado por los miembros de las dos principales culturas que habitaban en Madrid. Esto era y ha sido relativamente normal en los lugares donde se produce un contacto entre distintas religiones, siendo precisamente una de las características de los santos, su carácter sincrético y conciliatorio, que posibilita ser aceptado por los miembros de distintas comunidades (Fernández Montes 1999: 20). Por otra parte los milagros de tipo hidráulico (producción de lluvias y aparición de manantiales) son de gran importancia en las hagiografías islámicas que tienen su principal escenario en áreas geográficas subdesérticas. El moro no es castigado por haber osado rogar a un santo cristiano, sino por el incumplimiento de un voto.

Lo mismo le ocurrirá a un soldado cristiano de Córdoba que, tras caer cautivo en 1270, implora la intercesión de un santo y San Isidro se le aparece en un sueño nocturno librándole de las cadenas. Por ello hace el voto de ir a visitar su sepulcro, incumpliéndolo "por la oposición de su familia", por lo cual, al poco tiempo volvió a caer prisionero y tuvo que repetirse nuevamente el voto y la prodigiosa salida de la cárcel, siendo esta vez cumplida la promesa (Anónimo 1993: 131-132). Otros tres libramientos del cautiverio son mencionados en la segunda serie de milagros; aunque en estos casos no se indica la causa de la prisión, nos señalan claramente que ésta era una de las demandas de la sociedad medieval.

Asimismo, en otras tres ocasiones, el Códice nos narra milagros-castigo provocados por el incumplimiento del voto o por la falta de fe en un santo campesino, mostrándonos cómo es necesaria la reciprocidad; el culto es la contrapartida necesaria para obtener la mediación. El santo de baja condición social cuya devoción empieza a extenderse durante el siglo XIII, resulta totalmente novedoso, ya que en el modelo cristiano mayoritario hasta la época, la nobleza y la distinción social eran requisitos imprescindibles para alcanzar tal condición. No deja de ser significativo que los milagros-castigo por incumplimiento de votos o por incredulidad en varias ocasiones recaigan en individuos que o no son cristianos, como el moro citado, o no son madrileños, como el soldado, o un recaudador del impuesto real de la martiniega que llegó a Madrid y al tener noticia de San Isidro pronunció estas despectivas palabras:

Yo estaría dispuesto a creer que, quien fuese hijo de un príncipe o de un noble, bien pudiera llegar a ser verdadero santo; pero no creo de ninguna manera que llegue a santo un jornalero o un campesino (Anónimo 1993: 125).

El trastorno nocturno con que responde el santo ante este último individuo, eminentemente impopular, cuya estancia se debería considerar 
como non grata por todos los habitantes, nos recuerda actuaciones muy semejantes de los santos islámicos (Rodríguez Mañas 1991) que frecuentemente intervienen para evitar los abusos de la autoridad y el poder, siendo los recaudadores de impuestos uno de los grupos en los que recaen sus milagros-castigo y recordándonos que el modelo de santidad musulmán, presente en la leyenda de San Isidro, no fue eliminado de forma brusca sino que perduró y afloró repetidas veces en los siglos siguientes. Pero, lógicamente, no son este tipo de intervenciones las que le granjearon la popularidad y extensión del culto, sino aquellas otras en las que la población recibe un beneficio palpable.

En primer lugar, Isidro destaca como mediador para obtener lluvias en primavera, lo que, según el Códice, le demandan no sólo los campesinos de Madrid, sino también los de los alrededores, confirmando el apodo de labrador de nuestro santo, el carácter agrícola de la población y la lenta pero imparable extensión del culto a las áreas y aldeas limítrofes. Es la petición principal de los tres primeros milagros póstumos (Anónimo 1993: 123-125) donde se detalla minuciosamente el procedimiento:

12. También por designio de la Divina Providencia, a causa de la maldad de los hombres, en una primavera, la cosecha peligraba por falta de lluvia y apremio de la sequía. Por ello, tanto el clero como el pueblo estuvieron de acuerdo en la decisión de sacar del sepulcro a San Isidro y colocarlo solemnemente en un pedestal delante del altar de San Andrés Apóstol, de cara al crucifijo, e insistían con vigilas, cánticos, rezos y con cuidado de tener las velas encendidas para que el Señor se dignase, por sus merecimientos y rezos derramar lluvia sobre el campo $y$, librándoles del peligro remediar sus necesidades. Y esto fue cumplidamente alcanzado por la Misericordia Divina y los merecimientos de San Isidro, por lo que después hicieron muchas veces lo mismo en situación semejante y "su esperanza no se vio defraudadan.

El Códice concluye con la narración de una rogativa, que en realidad pertenece a la primera serie, pero al mencionarse que era la última, se colocó en este lugar. El relato es de tal fuerza y expresividad que se constituye en un testimonio valiosísimo sobre este tipo de episodios en la Edad Media castellana, por lo que no podemos resistirnos a su reproducción:

Entre otros milagros conocidos que se atribuyen a San Isidro, en modo alguno debe pasarse por alto el que por la divina misericordia se reveló a todo el pueblo de Madrid, tanto clérigos como laicos y otra mucha gente venida de diversas partes para rogar lluvia en el año 1275, en el mes de marzo, bajo el reinado del Rey Don Alfonso. Como a la sazón, la escasez de alimentos y pan apremiase a todo el pueblo, a lo largo y ancho de la región y la excesiva hambre diezmara a mendigos y pobres, y el cielo no concediese lluvia para las semillas sembradas en la tierra, muchos pueblos de los alrededores, con el estandarte de la Cruz delante, 
iban en masa a visitar distintos santuarios y del cielo reclamaban la lluvia con lágrimas y suspiros. En esta difícil situación, todo el pueblo de Madrid, tanto el Cabildo de clérigos como el Concejo de legos y el Colegio de los religiosos, unánimemente llegaron al acuerdo de sacar la reliquia de San Isidro del sepulcro y, por su mediación, rogar lluvia al cielo. Así se hizo, y los franciscanos, colocando el lecho sobre sus hombros, llevaron la reliquia del Santo hasta la Basílica de Nuestra Señora la Virgen María, que dista de la villa casi dos millas, y, en compañía del clero y de todo el pueblo, lo llevaron en procesión con gran solemnidad. $\mathrm{Y}$ allí se encontraron que había una gran muchedumbre de Yllescas con la imagen de Nuestra Señora la Virgen María en espera de la lluvia del cielo. Y, una vez celebrados los oficios divinos adecuados y acabado el sermón, como la lluvia no caía del cielo ni se dignaba llegar a la tierra, la gran multitud de los presentes, en medio de lloros, clamaba y gemía muy atemorizada, porque el Señor no consentía mandar lluvia ni siquiera por intercesión del Santo, quien mientras vivió, con insistente denuedo, había visitado la Basílica de la Virgen. Entonces el predicador dijo: "Sáquese el dignísimo cuerpo de lugar donde reposa, tiéndasele delante de la Virgen María y hágase así lo que Dios ha decidido dar por buenon. Inmediatamente después las manos de los religiosos levantaron el cuerpecillo del Santo y todos de corazón se deshacian en lágrimas, gemidos y llantos. Plugo a la divina providencia derramar abundante lluvia del cielo y regar sobradamente la región [...]. Tras devolver el cuerpo del Santo a su sepultura, todos volvieron a sus casas con gran regocijo, y aquel año, por la misericordia divina, todos los campesinos obtuvieron una cosecha abundante en todos los lugares de la región (Anónimo 1993: 145-146).

Si en la leyenda de San Isidro, la imprecisión es absoluta y la única mención a alguna advocación (Santa María Magdalena) como ya mostré (Fernández Montes 1999: 38-41) cronológicamente es casi totalmente imposible que existiese en el Madrid del siglo XII, y más bien se corresponde con el del finales del XIII, ahora se menciona el culto mariano, en una basílica dedicada a Nuestra Señora la Virgen María. Ésta se identifica con la Virgen de Atocha que, aunque hoy ha quedado incluida en Madrid, durante buena parte de su historia fue efectivamente una basílica rural (Fita ${ }^{4}$ 1886: 152-153), situada en Tocha donde se hallaba una dehesa y otra zona de huertas, probablemente era el principal destino de las romerías y rogativas madrileñas. También el culto a la Virgen en Madrid ha quedado reflejado en otra petición de lluvias, después de la cual, un sacerdote corta la cabellera a San Isidro para llevarla a la iglesia de Santa María (con toda probabilidad se refiere a la Almudena, aunque todavía no se la cita con este nombre). Su extensión por toda Castilla La Nueva, tras la toma cristiana de los territorios fue muy amplia ya que, a falta de reliquias de santos para consagrar las iglesias o ermitas y convertirlos en

${ }^{4}$ La existencia de la basílica cle Atocha está atestiguada al menos desde 1201, cuando su prior aparece como confirmante en la venta de unos territorios. 
patronos o mediadores, para venerar o tomar como patrona a la Virgen tan sólo se requería una imagen y por tanto fue mayoritario en la mitad meridional de la Península (Christian 1991: 47), siendo la advocación prioritaria de las mezquitas que se reconvirtieron en iglesias.

Por otra parte, también interesa resaltar que en la primera serie de milagros son constantes las alusiones al clero, cuyos miembros son con frecuencia los beneficiarios de los milagros, además de reiterarse la frase: "por acuerdo del clero y el pueblo". Las referencias a los franciscanos que hicieron suponer que pertenecía a esta religión el autor del Códice se deben sin duda a ser la orden dominante en el Madrid bajomedieval.

El poder de San Isidro como santo sanador, especialmente de enfermedades incurables, para las que, como se menciona en más de una ocasión, "Se había perdido toda esperanza en los remedios médicos" es el tema principal de los milagros póstumos del Códice, ajustándose en esto con bastante fidelidad al modelo de santidad cristiano de la época, que persistirá y se mantendrá prácticamente hasta nuestros días.

En primer lugar destacan las curaciones de cegueras, totales o parciales, de las cuales se contabilizan cinco relatos antes de los himnos y diez y seis después, mostrando estos veintiún milagros, los de mayor peso numérico en el Códice, la principal demanda e intervención del santo en el siglo XIII, poder que le vuelve a asemejar a los santos islámicos y que perderá en los siglos siguientes. Muy por debajo, le siguen en importancia las siete curaciones de parálisis (tres en la primera serie y cuatro en la segunda). En todos los casos se menciona cómo el enfermo debe ser guiado ante el sepulcro por causa de su ceguera o trasladado en mulas por la inmovilidad.

Mucho más esporádicas son el resto de sus intervenciones ante otras dolencias de las que tan sólo se cuentan uno o dos milagros, como la curación de un tullido (en la $1 .^{\text {a }}$ serie), devolver el habla a una muda (en la $2 .^{a}$ ), curación de un dolor de muelas a un sacerdote $\left(2 .^{a}\right)$, anginas, a un soldado de Guadalajara (1. ${ }^{a}$ ) (con este episodio además se quiere indicar la extensión del culto, al igual que con el ya comentado suceso del soldado de Córdoba), dos curaciones de esterilidad (una en cada serie), una enfermedad grave, sin especificar $\left(1^{a}\right)$ y la resurrección de un joven (2.). A estas curaciones, que hoy en día en algunos casos no nos parecen tan prodigiosas, pero que sin los analgésicos y remedios médicos actuales podían trastornar gravemente la salud, hay que añadir tan sólo dos casos de tercianas o cuartanas ${ }^{5}$ y uno de fiebre, lo que nos sorprende

\footnotetext{
5 Las tercianas y cuartanas son modalidades de fiebres palúdicas, provocando, una vez contraídas, episodios de alta fiebre periódica que se repiten a lo largo de toda la vida del afectado. Constituyeron un verdadero azote de las localidades castellanas, al
} 
por su escasez, pues, a partir del siglo xvI, las calenturas se convertirán en la verdadera especialidad del santo, si bien es cierto que el remedio no se obtenía visitando el sepulcro, sino bebiendo del agua de su manantial, del que no existe todavía ninguna referencia.

Entre sus intervenciones como santo sanador, nosotros añadiríamos dos libramientos del demonio, aclarando que se trata de estados de desasosiego e inquietud que provocan el insomnio (en una de las narraciones afectando a un moribundo) y no de la posesión convulsivo-demoniaca (en muchos casos ataques de epilepsia) que se remedia con los exorcismos. En otro relato, el demonio se le aparece a un sacerdote por la noche, mientras hacía una vigilia al santo, en forma de niño negro, lo que fue una constante en las hagiografías europeas.

Comentario independiente merecen las curaciones a jóvenes de ambos sexos; en tres ocasiones se detalla que eran hijos de caballeros o de personas honradas. Sin especificar su condición se mencionan también otros cuatro sucesos que beneficiaron a tres muchachos y una joven. Frente a éstos, sólo hay una curación de un niño de cuatro años. En todos los casos, excepto el de la joven que recuperó el habla, los relatos nos cuentan cómo de forma repentina sobrevino la ceguera de un ojo, o la parálisis de uno de sus miembros y transcurrido un tiempo sin remedio médico, se acude al santo, tras lo cual se recupera la vista o el movimiento:

16. [...] a un joven de las afueras de Madrid llamado Domingo Pérez cuando volvía del somonte a su casa con sus compañeros, de repente le sobrevino en el camino una parálisis momentánea de sus miembros, hasta el punto que no podía moverse en absoluto. Cuando los compañeros avisaron a su familia, sus padres lo llevaron a casa a lomos de una bestia. $\mathrm{Y}$ al percatarse sus padres de que no le surtían efecto los emplastos, ungüentos, abluciones y otros remedios aplicados durante largo tiempo, prometieron llevarlo al sepulcro del Santo [...] La noche siguiente el Santo siervo de Dios se le apareció en sueños al joven y le dijo estas palabras: "Domingo, hijo, yo Isidro, uno más ente los servidores de Dios, te aconsejo que te frotes con este bálsamo y ten por cierto que recobrarás la salud". [...] al instante reconfortaron su cuerpo con el bálsamo indicado por el Santo. Y de forma prodigiosa, tras la primera y única aplicación, el joven recobró enteramente la salud en todo su cuerpo [...] (Anónimo 1993:126-127).

45. Una muchacha, llamada Romera, que estuvo sin vista en un ojo durante largo tiempo, fue llevada por sus padres ante el sepulcro de San Isidro. Y, tras pedir la ayuda del Santo, recuperó la salud antes de nueve días (Anónimo 1993: 141).

Relatos semejantes encontramos también afectando a adultos de ambos sexos, pero destacamos los de los jóvenes porque, aún sin ánimo de

menos a partir del siglo xvi, cuando se comienzan a reflejar las dolencias características de cada localidad en las sucesivas Descripciones Geográficas de la Edad Moderna. 
minusvalorar la intervención de San Isidro, en la actualidad, cualquier neurólogo encontraría en la esclerosis múltiple la explicación de estos males repentinos y sus curaciones prodigiosas ${ }^{6}$.

Por último, queremos recapitular sobre la condición social de los beneficiarios de los milagros póstumos. En tres de los cinco realizados en vida, el propio Isidro, considerado como un humilde campesino, es quien recibe algún provecho. Así sucede cuando se multiplica la harina aprestada para sus necesidades tras la molienda, después de haber dado gran parte del grano a unas palomas; o al arar los bueyes sin guía, para que él pueda dedicar parte de su jornada a la oración; al igual que cuando no muere su jumento, atacado por un lobo, al que no socorre por no interrumpir sus rezos. En los otros dos milagros, los agraciados son los pobres a los que se destinan sendas multiplicaciones de alimentos. Pero en los prodigios obrados gracias a su mediación, a través del culto al cadáver, varía completamente este carácter claramente popular para, en la mayoría de las ocasiones, ponerse al servicio de las clases dominantes, quienes sin duda promovieron y alentaron el culto.

En primer lugar vuelve a destacar el propio Isidro, pero no como campesino, sino como una reivindicación del santo local; él es el principal beneficiario cuando los milagros se producen para el establecimiento o mantenimiento de su culto (descubrimiento del cuerpo, toque de campanas durante la traslación y castigos a incrédulos), contabilizándose cinco actuaciones en la primera parte del Códice y tres en la segunda. A éstos habría que añadir los dos milagros que afectan al mayordomo de la cofradía de San Isidro y a "un antiguo servidor del santo".

Tras él, los religiosos acaparan buena parte de las intervenciones de la primera serie de narraciones que benefician a un porcionero de la iglesia de Santa María, un fraile franciscano, un sacerdote del cabildo y un sacristán. Frente a estos cuatro casos, tan sólo un franciscano es mencionado en la segunda, pero en su conjunto nos informan con bastante claridad de cómo fue este sector social el que inició y promovió el culto.

Las personas de elevada condición también son mencionadas con profusión en los milagros póstumos que anteceden a los himnos, lo que asimismo resulta ilustrativo del protagonismo de esta clase social en la fundación de la cofradía de San Isidro y la extensión de su culto. Como

\footnotetext{
${ }^{6} \mathrm{La}$ esclerosis múltiple o esclerosis en placas es una enfermedad del sistema nervioso que se manifiesta por primera vez en la juventud, cesando sus brotes antes de llegar a los cincuenta años. Se caracteriza por la aparición de crisis periódicas que provocan pérdidas de la visión, el oído o parálisis y de las que el paciente, al menos en sus primeras manifestaciones en las variantes menos graves, se recupera de forma espontánea en pocas semanas.
} 
tales consideramos las menciones a: "una mujer casada de buena fe", "una virtuosa mujer", o el "hijo de una mujer honrada", esta última tenía "criadita". También los prodigios que afectaron a un caballero, al hijo de otro caballero, al de un hombre honrado y a otro individuo que, tras su curación, alimentó a los pobres y lo gastado en ellos se restituyó milagrosamente.

En contrapartida, los pobres sólo fueron agraciados con las curaciones prodigiosas que se sucedieron en el momento de la traslación del cadáver y con la multiplicación de alimentos para que el mayordomo pudiera dar un mayor número de caridades. A ellos, por su baja condición social, tan sólo se puede sumar una humilde mujer de la alquería de Leganés.

Sin ofrecer dato alguno sobre su condición social, se contabilizan catorce hombres y ocho mujeres, todos los casos relatados en la segunda serie, donde las narraciones son mucho más breves e imprecisas. Por otra parte, ya hemos destacado su poder taumatúrgico en milagros hidráulicos cuyos beneficiarios son los campesinos madrileños y comarcanos y se podría decir que la sociedad en general, dentro de una economía agraria donde las sequías provocaban carestía, hambre y epidemias.

Resulta sorprendente, y a la vez significativo que, frente a la generosidad con los pobres e incluso con las aves que refleja la leyenda de San Isidro, en los milagros póstumos tan sólo se relata una multiplicación milagrosa de alimentos para los indigentes que, según la norma, el mayordomo de la cofradía de San Isidro debía dar de comer (Anónimo 1993: 139-140). Gracias a este relato conocemos que en el último tercio del siglo XIII ya estaba instaurada en Madrid esta institución, lo que parece bastante lógico, teniendo en cuenta la existencia del cuerpo y el Códice, donde se certifica el establecimiento del culto. En otra narración fechada en 1266 (Anónimo 1993:129), en la que se cura de ceguera a un sacerdote del Cabildo de Madrid, se menciona cómo éste estaba encargado de preparar el convite colectivo para la "hermandad de una cofradía de clérigos seglares y de franciscanos", lo que nos señala a los religiosos como protagonistas pioneros en la fundación de las cofradías madrileñas.

Por último hay que destacar la total ausencia de referencias a la intervención más discutida y polémica del santo. Nos referimos a su aparición en forma de pastor, ante el desorientado ejército cristiano que conducía Alfonso VIII, en la batalla de las Navas de Tolosa. Sus indicaciones del camino idóneo para tender una emboscada provocarían la victoria sobre las huestes musulmanas en 1212. Pero del relato no se tienen referencias hasta el siglo xVI y, como resulta fácil mostrar, es cronológicamente incompatible, ya que en estas fechas se estaba descubriendo el cadáver e iniciándose el culto. Además la narración, según la cual Alfonso VIII des- 
pués de la batalla pasó por Madrid y al visitar el sepulcro y ver el cuerpo incorrupto de San Isidro, lo identificó con el pastor que les guió, se contradice con las crónicas reales que cuentan cómo el monarca se dirigió directamente a Toledo. Las acaloradas polémicas sobre esta aparición que han generado ríos de tinta, personalmente nos resultan sumamente gratas y oportunas, puesto que es el único episodio en el que el santo toma partido por una religión o grupo social, contradiciendo su carácter sincrético y conciliatorio. En cualquier caso hay que resaltar que la identificación del pastor con el patrono de Madrid, no se realiza hasta siglos después, cuando el ambiente de intolerancia religiosa y social fue en aumento dentro de la Península.

\section{LOS HIMNOS EN HONOR A SAN ISIDRO}

El nuevo carácter que San Isidro adquiere con sus intervenciones en el siglo XIII no anula ni aparentemente entra en contradicción con las cinco narraciones que cuentan sus intervenciones mientras estuvo vivo en el XII, sino que estas primeras también mantienen su vigencia y siguen relatándose y transmitiéndose, aunque transformadas y acomodadas a la nueva sociedad; son los pilares del culto al cadáver, como nos muestra el contenido de los oficios que se cantaban en su honor dentro de la iglesia de San Andrés.

El primero de los seis himnos que separan las dos series de milagros póstumos recogidos en el Códice, está dedicado al episodio más famoso en el que, al ser espiado por su amo, tras la acusación de que abandonaba el trabajo para rezar, éste ve cómo los bueyes aran solos. Como ya mostramos (Fernández Montes 1999: 31-41), el relato contiene significativos paralelos con las hagiografías islámicas, pero muchos de estos aspectos quedan ahora plenamente cristianizados. En primer lugar destaca, como también ocurría en las narraciones antes comentadas, que Isidro aparece como un devoto de la Virgen María, cuyos altares visita no sólo en las iglesias madrileñas, sino también en las ermitas cercanas; mientras que en el relato original, el santo acudía a las iglesias para orar sin mencionarse ningún culto o advocación. La segunda modificación, de mayor repercusión por haberse impuesto plenamente en todas las versiones posteriores y caracterizar al personaje, es la aparición de un ángel guiando los bueyes, que en la primera versión araban sin ayuda. Persisten algunas características de la narración primitiva, como la acusación de los vecinos sobre el comportamiento del santo, o la ira del amo, aunque en su reconciliación final se lanza un significativo mensaje a los campesinos, 
a la vez que el santo labrador se acerca a los intereses de los amos propietarios:

El propietario, satisfecho porque con exactitud cada año se le pagan las rentas con el montante de una rica cosecha, lo dejó todo al cuidado del fiel siervo de Dios (Anónimo 1993: 134).

El segundo himno tiene como tema el carácter humilde de San Isidro: El pobre que es elegido por Dios y queda sentado entre los príncipes y reyes; se trata de una reivindicación de la autenticidad del personaje que encaja dentro de los nuevos patrones de santidad, que tímidamente se empiezan a difundir por Europa. El tercero mantiene el mismo carácter, aduciéndose las pruebas o signos inequívocos de su condición, como el fragante olor de su cuerpo incorrupto, "regalo de Dios" y su capacidad para provocar lluvias cuando se le saca del sepulcro. Prosiguen los siguientes, señalando algunos aspectos del culto, como los propios salmos que se le cantan y los presentes que se le ofrecen en el cuarto himno, donde nuevamente se alaba que sea ayudado por los ángeles en su trabajo y la multiplicación milagrosa de alimentos destinados a los pobres tras el banquete de una cofradía. En el quinto se reitera la existencia del cuerpo incorrupto como un regalo, finalizando el último con una bella exhortación al culto del humilde campesino, en la que se enumeran religiosos y nobles, maestros, jóvenes casadas, doncellas, etc. Destaca una mención expresa al Cabildo y Concejo de Madrid que indudablemente comienzan a reivindicarle como santo local, a lo que se añade más abajo que su capacidad taumatúrgica está atrayendo a forasteros que imploran y obtienen su mediación (Anónimo 1993: 133-138).

\section{EL ARCA PRIMITIVA COMO TESTIMONIO DEL CULTO EN EL SIGLO XIV}

Frente a la riqueza de datos contenidos en el Códice del siglo XIII, para la siguiente centuria apenas contamos con testimonio alguno sobre la religiosidad madrileña y en concreto sobre San Isidro. En realidad, se desconoce hasta dónde se generalizó el culto en la Comunidad de Villa y Tierra de Madrid, si realmente comenzó a ser difundida y reconocida su santidad o se circunscribía a la parroquia de San Andrés y su cofradía. Aunque la existencia de un cuerpo incorrupto en que centrar los actos, desde luego era una baza muy importante para su difusión, frente a otras advocaciones que en el mejor de los casos tan sólo podían contar con minúsculas reliquias de más que dudosa credibilidad. También la cofradía debió de ser un aglutinante importante, pues lo normal, al menos en es- 
tas fechas es que prácticamente la totalidad de los madrileños pertenecieran a ella, sin menoscabo de participar en otras, si es que las había.

Pero la ausencia de noticias escritas se suple en parte con la llamada arca primitiva. Según la tradición fue regalada por Alfonso VIII en agradecimiento por su intervención en la batalla de las Navas de Tolosa, pero en realidad, por los motivos arquitectónicos que adornan los arcos que, a modo de viñetas separan unas escenas de otras, además de la composición y diseño de las propias figuras, se fecha a finales del siglo XIII $\mathrm{O}$ más bien en la primera mitad del XIV.

Aquí yació el cuerpo del santo al menos desde la primera mitad del XIV, hasta 1620 , cuando con motivo de las fiestas de su beatificación fue trasladado al arca de plata que regaló el gremio de plateros de Madrid. Aunque en la actualidad ha sido restaurada (Priego 1994: 7), desde fechas muy tempranas se deterioró tanto que se hicieron irreconocibles los motivos que adornaban la tapa. Sí se identifican con claridad algunos temas, como la escena de los ángeles arando con bueyes (que probablemente por su

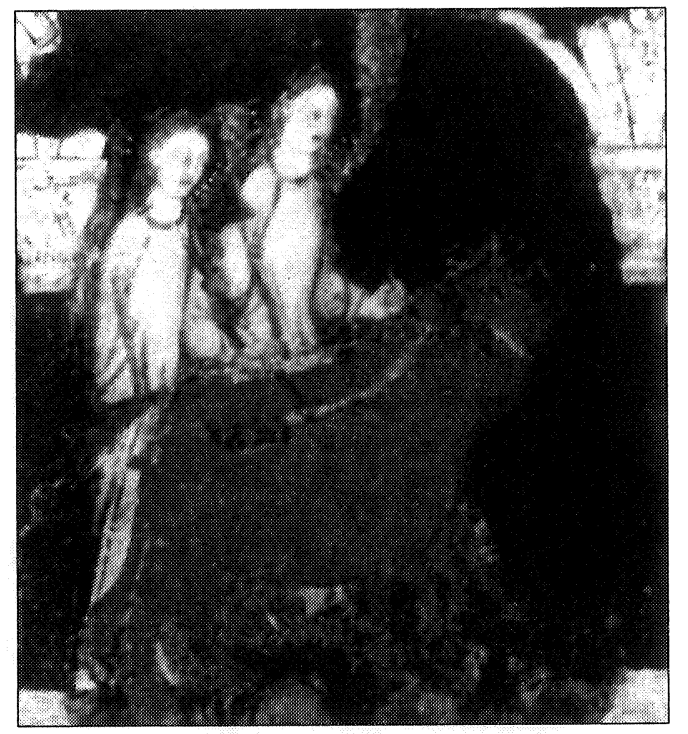

FIGURA 1.-Arca primitiva de San Isidro. Detalle: Ángeles arando.

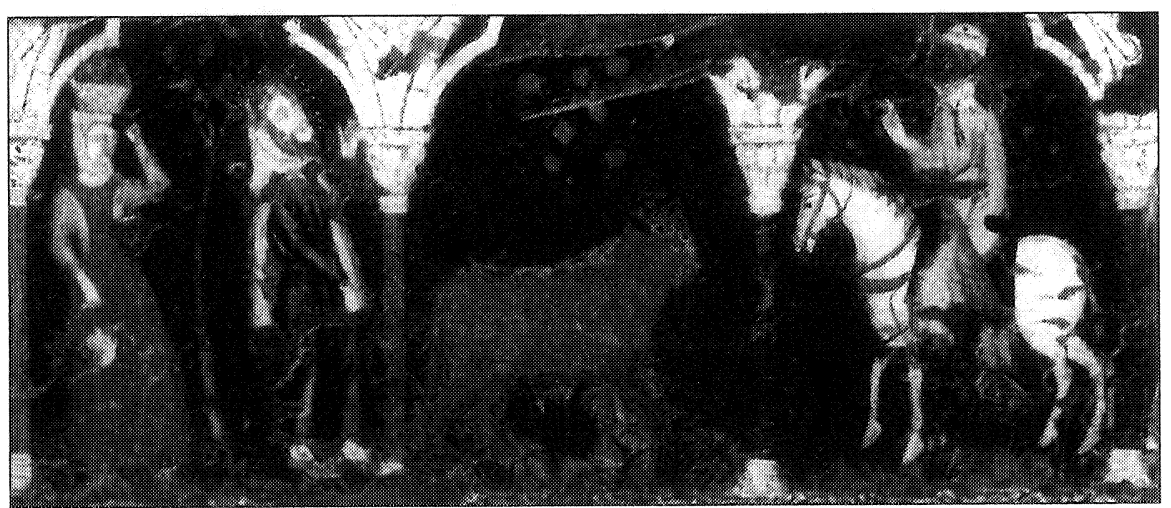

Figura 2.-Arca primitiva de San Isidro. Detalle: San Isidro arando es vigilado por su amo, mientras su esposa le acerca la comida. 


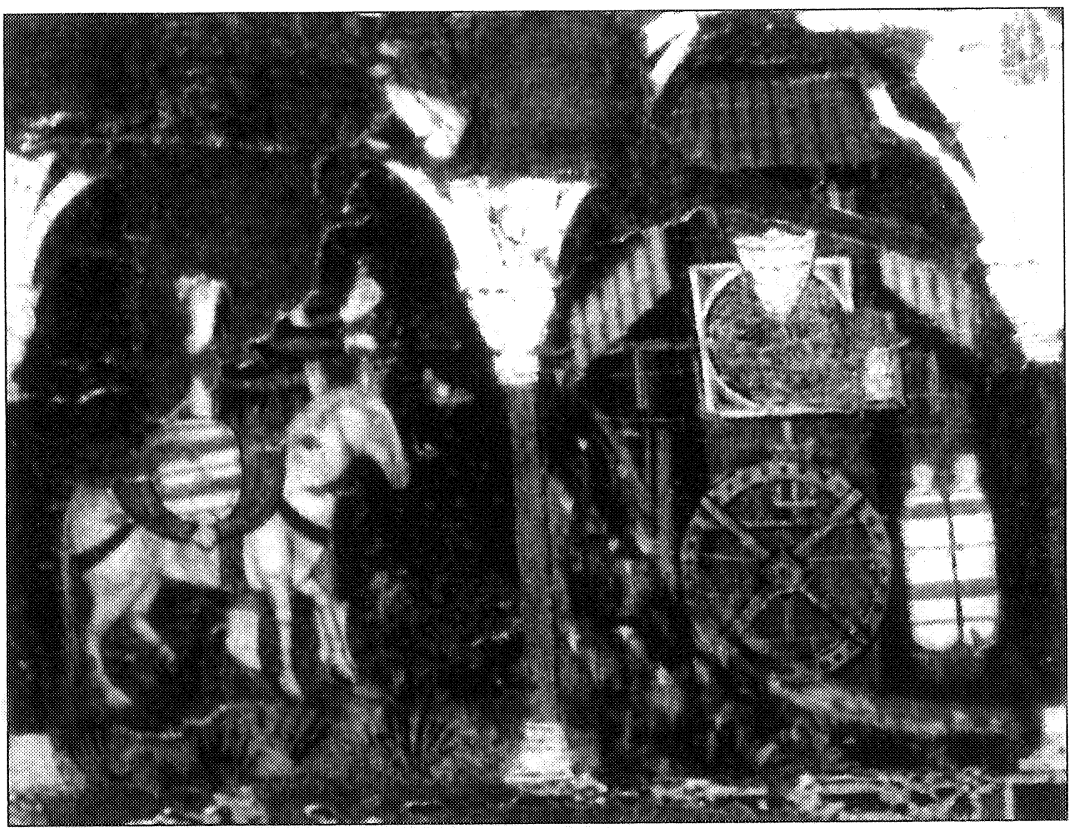

FIGURA 3.-Arca primitiva de San Isidro. Detalle: San Isidro alimenta unas palomas con el grano que llevaba a moler, y tras la molienda se multiplica la harina.

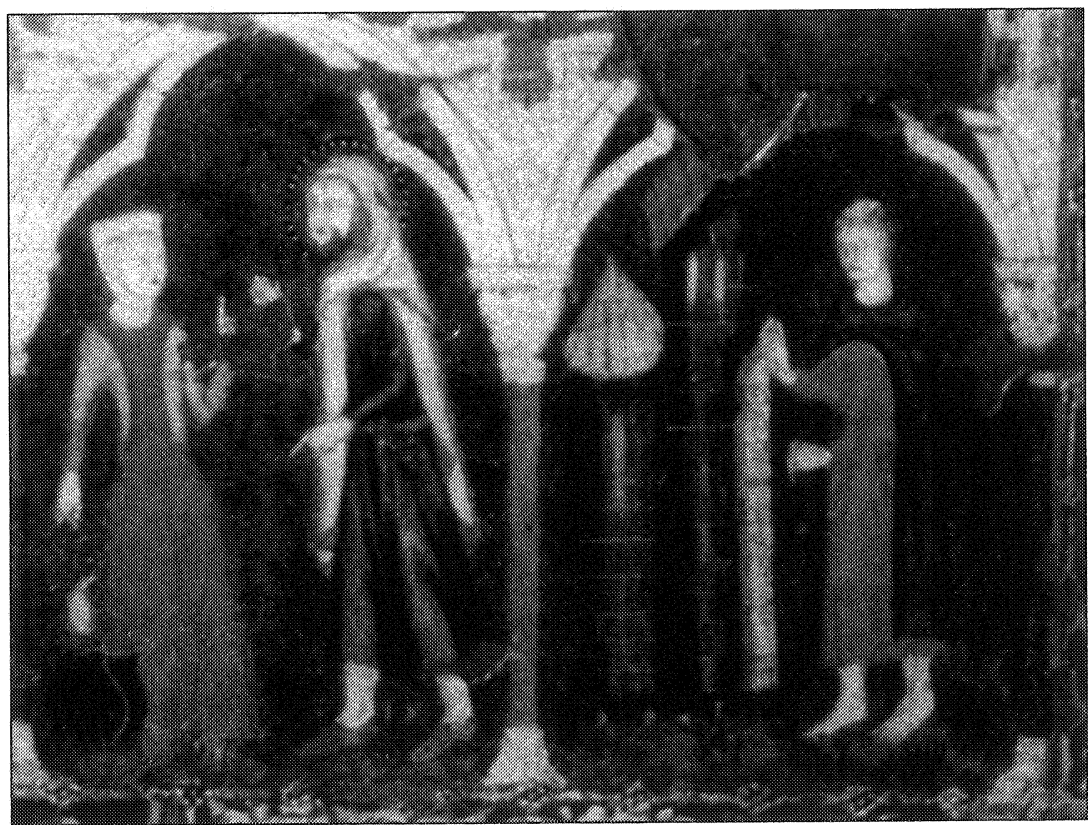

FIGURA 4.-Arca primitiva de San Isidro. Detalle: Multiplicación milagrosa de la comida que había en una olla para dársela a un pobre. 
mayor vistosidad, no son del color blanco que menciona el Códice, sino naranja), en otra viñeta el amo a caballo vigila al santo que está arando personalmente y su mujer le acerca la comida. Isidro, identificado por una orla sobre su cabeza, viste pobremente, sayo largo y turbante aunque su esposa aparece con indumentaria plenamente cristiana.

Ambos vuelven a aparecer dentro de un edificio, mientras un pobre, descalzo, espera a la puerta (milagro de la multiplicación milagrosa de alimentos, sucedida en su casa). En buen estado se ve un molino y más deteriorado a San Isidro en burro (parte de la represen- Figura 5.-Arca primitiva de San Isidro. Vista de un lateral. tación de la multiplicación milagrosa de la

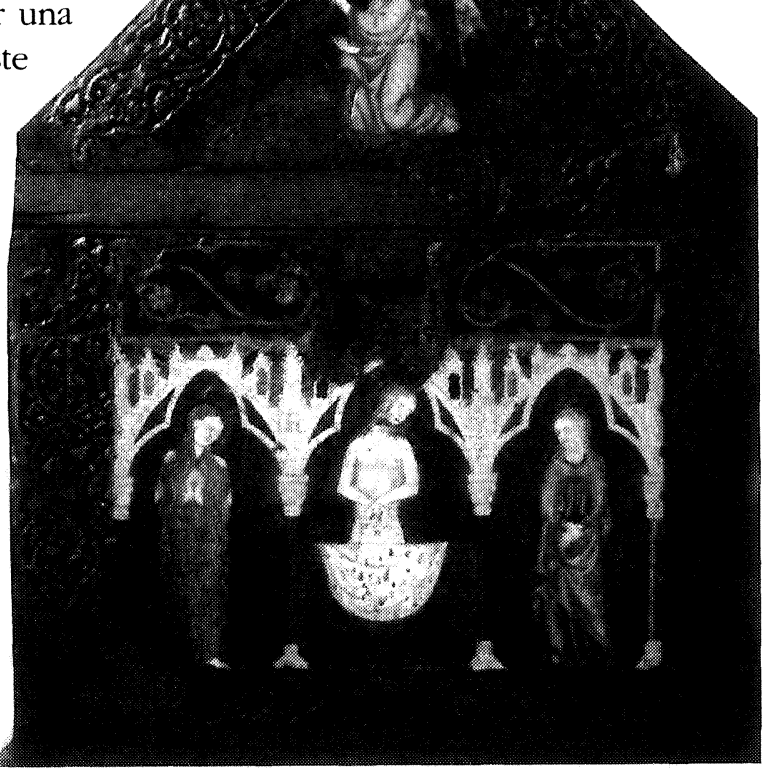
Resurrección de Jesucristo ante María Magdalena y la Virgen.

harina tras alimentar unas palomas con el grano).

En la tapa se puede reconocer a Isidro de rodillas orando ante una imagen entronizada de la Virgen y en otros dibujos, los más deteriorados, aparece sentado a la mesa con otros personajes (imilagro de la multiplicación de alimentos para los pobres tras la celebración del banquete de una cofradía?). Los dos laterales están muy bien conservados, destacando la representación en uno de ellos de la resurrección de Jesucristo en el medio, flanqueado por la Virgen María y María Magdalena, cuya advocación ya quedó recogida en los cinco milagros que realizó en vida según el códice medieval.

Del resto de los dibujos poco más se puede identificar en la actualidad, pero naturalmente existen relaciones antiguas como las recogidas por Zacarías García Villada (1922: 76), realizadas por los Notarios Apostólicos, Velázquez y Manrique que reconocieron el arca en 1598 diciendo de ella: 
Y a los pies del dicho retrato está una caja grande de hasta tres varas de larga, toda pintada de diez y seis milagros del dicho Santo, y en especial cuando le multiplicó Dios las ollas para dar a los pobres y el milagro del arado y la fundación de la fuente y la resurrección del caballo de su amo.

Como el propio Zacarías García Villada indica, de los dos últimos milagros descritos no queda ningún testimonio reconocible en la actualidad (a no ser que el amo subido en su caballo se haya interpretado como el milagro de la resurrección del animal) lo cual hace dudar de la interpretación de finales del XVI, puesto que de ambos no hay ninguna mención en el Códice y supondrían nuevas aportaciones a la hagiografía de santo que, por lo que sabemos, no se incorporaron hasta, al menos un siglo después, o incluso más tarde. El propio García Villada, algo más abajo (1922: 77) detalla lo que él pudo distinguir a principios del siglo $\mathrm{xx}$ :

Lo que parece más cierto es que, en el primer cuadro, empezando de izquierda a derecha, está la Virgen con el Niño Jesús sentada en un trono, teniendo en los dos dedos de la mano derecha una manzana colorada. Arrodillado se ve a Isidro, que se distingue perfectamente por su traje. En el segundo cuadro hay otro grupo muy parecido al anterior, aunque bastante más deteriorado. Quizás recuerden estos grupos la devoción de Isidro a Santa María de Atocha y de la Almudena, patrona de Madrid. Los compartimentos tercero cuarto y quinto son indescifrables. En el sexto parece que están representados los desposorios de los Santos, no cabe, por lo menos, duda de que los personajes son ellos, pues así lo manifiesta su indumentaria. El séptimo compartimento contiene un edificio, que puede ser casa o templo y dos figuras: una vieja, al parecer ciega; la otra, con traje colorado, no sabemos que puede representar: lo que sí parece es que está en ademán de curar milagrosamente la vista a la ciega.

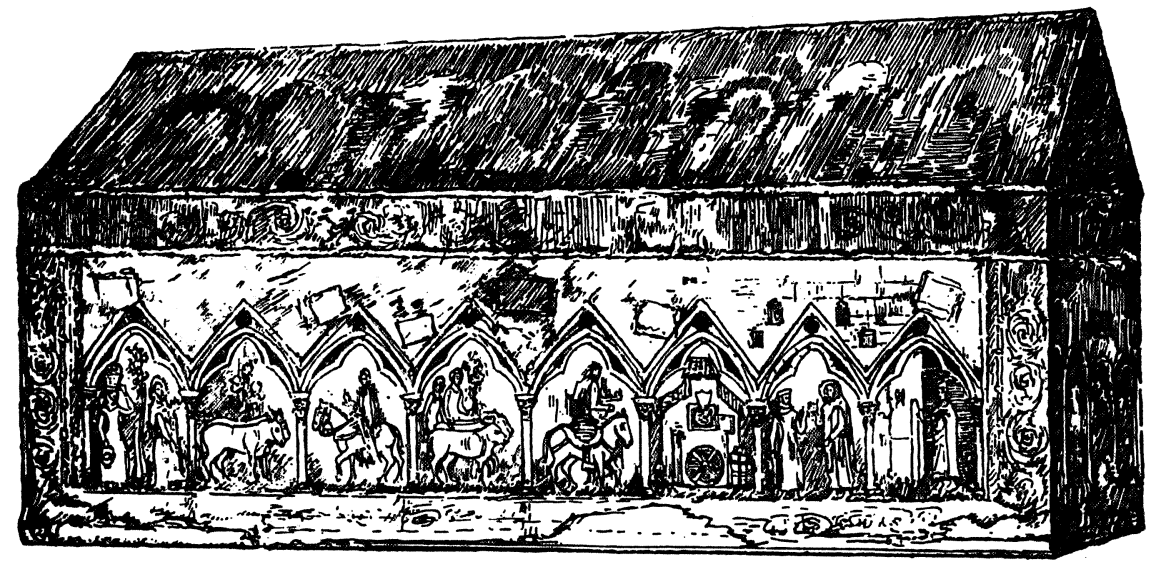

FiguRA 6.-Arca primitiva de San Isidro según Fidel Fita. 
Tampoco las descripciones del sexto y séptimo compartimento se corresponden con lo apreciable tras la actual restauración. La imagen del individuo montado a caballo, ya sea interpretada como el amo vigilando a Isidro, o como la primera referencia a la resurrección del equino de éste, sí resulta indicativa del peso que los caballeros madrileños, la clase laica dominante, están cobrando en el culto y más concretamente de la importancia y antigüedad del linaje de los Vargas que reivindicarán ser los descendientes de Iván Vargas, el supuesto amo del Labrador.

A la información iconográfica obtenida por el estudio del arca, se puede añadir un documento depositado en el Archivo de la Villa y fechado en 1346 que fue transcrito y publicado por Domingo Palacio (1888: 289-292) y que se constituye en el único manuscrito del siglo XIV que ha llegado hasta nosotros. Según éste, se condena al Concejo a pagar a Gonzalo Díaz seiscientos maravedies por "sacar el cuerpo sancto de sant esidro" siguiendo el mandato del alcalde de Madrid. En el título que se ha dado al documento se habla de la exhumación del cadáver, lo que verdaderamente resulta problemático, pues según el Códice esta operación se realizó en 1212, siendo depositado el cuerpo incorrupto en la iglesia de San Andrés e iniciándose allí su culto que en ningún caso podría retrasarse mas allá del último tercio del siglo XIII, fecha en que se data el manuscrito. Más abajo, el documento que nos ocupa alude a la operación como assancto negocio" y se aclara que Gonzalo Díaz debió pedir prestado el dinero a los judíos. Así se podría interpretar que la cantidad que el Concejo de Madrid adeuda a este personaje es por sacar el santo cuerpo de la iglesia en una romería, rogativa $u$ otro acto similar. También existe la posibilidad de que lo que se esté pagando es el traslado, desde el primer sarcófago en el que se depositó tras su exhumación, al que hoy conocemos como el arca primitiva. En este último caso, el elevado coste de la operación indicaría la existencia o celebración de actos complementarios. Sea cual sea la posibilidad real, es significativo que el Concejo de Madrid, no sólo la orden de religiosos que habita en la iglesia de San Andrés o los miembros de su cofradía, está ya en esta época vinculado al culto del Labrador. Matilla Tascón (1986: 20) interpreta que el cuerpo fue sacado en 1344 para que lo contemplara Alfonso XI y que los elevados gastos se ocasionaron en las fiestas que se celebraron en el momento; lo que no parece descabellado, dada su alta cuantía y el hecho de que tenga que ser el Concejo el responsable de su pago por instancias de este rey. Según tradición recogida ya por escrito en el siglo $\mathrm{xv}$, durante la visita de Alfonso XI, su esposa arrancó un brazo al cuerpo con intención de llevárselo, pero inmediatamente, dentro de la propia iglesia, le dio un síncope que la puso en trance de muerte y del que no se recuperó hasta devolver la extremi- 
dad. La noticia no es inverosímil ya que el acaparamiento de reliquias era una práctica muy codiciada, a la que muy pocos (reyes e instituciones religiosas) podían optar. La imposibilidad de desmembrar el cadáver e iniciar así la dispersión geográfica de las reliquias y el culto será, como veremos a continuación, otra de las características de San Isidro, que decididamente opta por su papel de santo local y patrón de una villa.

UN SANTO MONÁRQUICO PARA UNA VILLA REALENGA EN LOS SIGLOS XV Y XVI

Isidro tan sólo era un santo más de una villa más, como tantos otros que proliferaban como mediadores y protectores en las poblaciones de la cristiandad europea. Para proclamar la santidad de un individuo y comenzar a rendirle culto, hasta 1234 , bastaba con la aprobación del obispo local. A partir de esta fecha, el papa Alejandro III se reserva el derecho a canonizar, pero los obispos siguen confirmando la elevación a los altares de los nuevos personajes locales que villas y ciudades proclaman como sus patronos, sin que existiera, en la práctica, una oposición real de las jerarquías superiores, hasta 1623, cuando, en plena Contrarreforma, el papado obtiene el control completo de los santos, precisamente con Urbano VIII, que había canonizado a San Isidro un año antes.

Pero, a Madrid y su santo, unidos de forma indisoluble, la historia les deparaba un giro espectacular en su destino. La villa fortificada por los árabes mantuvo su alcázar en buen estado de habitabilidad durante toda la Edad Media, además era paso obligado de las comunicaciones entre Toledo y las principales ciudades del norte peninsular a través de los puertos de Guadarrama y Somosierra. No es casual por tanto que los sucesivos monarcas cristianos pasaran temporadas en la localidad, ni que trataran de impulsarla concediendo fuero y ferias, además de, por supuesto, procurarse la mediación positiva del benefactor, visitando su sepulcro y así sancionando e impulsando la devoción. Ya hemos mencionado la supuesta visita en el siglo anterior de Alfonso XI. También a la tradición pertenece la apertura del sepulcro en varias ocasiones por Enrique II, quien se maravilló de la suave fragancia que desprendía el cuerpo, confirmando su carácter de reliquia sagrada.

Madrid había quedado constituida como una Comunidad de Villa y Tierra que dependía directamente del rey y éste debía granjearse el apoyo incondicional de las clases dominantes, especialmente la de los caballeros, siempre dispuestos a aportar sus personas, armas y siervos en los conflictos bélicos. El reconocimiento de la santidad del patrón local que ante los mismos reyes efectúa intervenciones milagrosas, sin duda era una 
baza importante que, por otra parte, no producía costes ni entraba en conflicto con otras advocaciones.

Las últimas hojas del códice del siglo XIII quedaron en blanco para que se pudieran seguir añadiendo milagros póstumos y así se hizo en 1421 y 1426, cuando dos presbíteros de la iglesia de San Andrés añadieron en castellano y latín respectivamente la narración de un acta de apertura y reconocimiento del cadáver y la de una rogativa para pedir lluvias. Queremos llamar la atención sobre algunos de los nombres de los testigos que asistieron al primer acto, destacando entre los legos tres miembros del linaje de los Vargas: Pedro de Vargas, Diego de Vargas y Fernando de Vargas (Fita 1886: 152-153). En la segunda figuran con nombres y apellidos quienes custodiaban el arca con el cuerpo de San Isidro:

[...] encomendando cinco llaves de la misma arqueta: la primera al Cabildo de los Clérigos, la segunda a Diego de Vargas, la tercera a Fernando de Vargas, la cuarta a Rodrigo Martínez de Córdoba, la quinta al clérigo Martín Sánchez.

[firma] Martín, un humilde presbítero (Anónimo 1993: 146 y Fita 1886: 153).

El linaje de los Vargas que reivindicaba descender de Iván Vargas (el supuesto amo de San Isidro), fue uno de los más antiguos e influyentes de Madrid durante la Edad Media e inicios de la Moderna, ocupando con frecuencia cargos relevantes en el Concejo. Su vinculación a San Isidro debió de ser un argumento de peso para el apoyo monárquico. El mismo Diego de Vargas vuelve a aparecer en otro documento fechado en 1481 y relacionado con el santo:

En lunes, ocho días de enero del dicho año de LXXXI.

Este día, estando ayuntado a conçéjo en la yglesia de San Saluador de la dicha Villa, a campana rrepicada segund que lo han de vso e de costunbre con el honrrado caullero Rodrigo de Mercado, corregidor en la dicha Villa por el Rey e Reyna nuestros señores, e con Joan Çapata el Moço e Diego de Vargas e [...]

El Dotor Alonso Ferrçandez de Madrid e bachiller Ferrando Díaz, letrados del dicho conçejo, e bachiller Jarada e [...].

De los onbres buenos pecheros, [...] e otros muchos.

Este día, otorgaron vna petiçión para la Reyna nuestra señora sobre la lauor de la Yglesia de Sant Esidre (Ayuntamiento de Madrid 1932: 59-60).

Diego de Vargas que había sido nombrado regidor de Madrid por Isabel la Católica en sustitución de su padre (Millares Carlo 1971: 25), es mencionado en una petición a la reina, relacionada con la iglesia de San Isidro, aunque no existía ninguna con este nombre en Madrid, por lo que se debe tratar de la de San Andrés, a la cual la soberana costeó una ampliación para que el cementerio donde estuvo la fosa del santo quedara incluido dentro del recinto sagrado. 


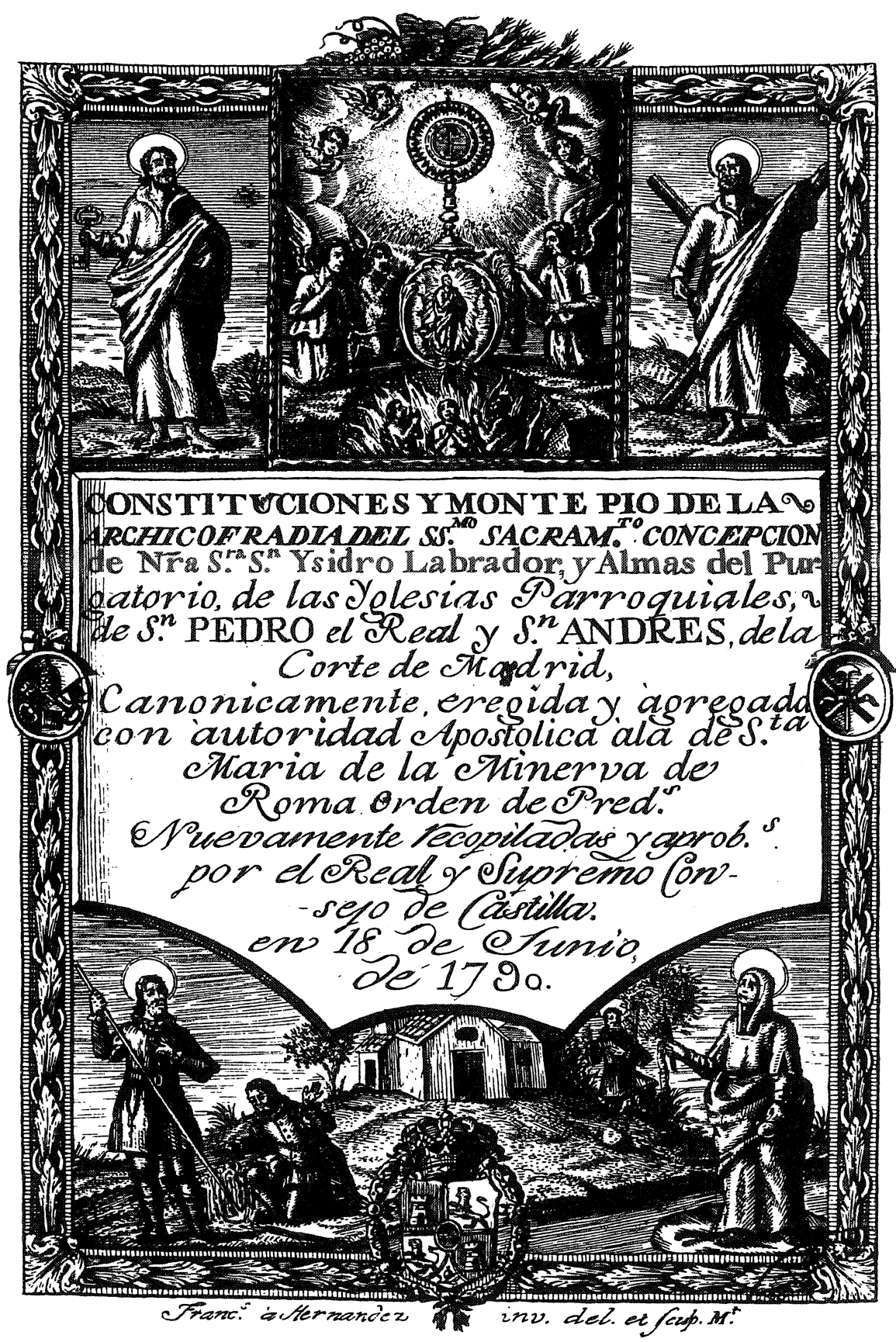

Figura 7.-Portada de las Constituciones y Monte Pío de la Archicofradía del Santísimo Sacramento, Concepción de Nuestra Señora, San Isidro Labrador y Almas del Purgatorio. 1790. 
Si los anteriores monarcas cristianos pasaron temporadas en la villa, su presencia se incrementará a partir del reinado de Isabel que junto con su esposo Fernando residió aquí algunos días en 1477; desde noviembre de 1482 a abril del 83; otra nueva breve estancia en 1486 y, casi un año entero, entre agosto de 1494 y mayo del 1495 (Matilla Tascón 1986: 32). Indudablemente los reyes visitaron el sepulcro del santo, al que cambiaron el sudario (costumbre que practicarán todos sus sucesores), asegurando la tradición que en una de estas visitas, una dama de la reina, so pretexto de besar el glorioso cuerpo, le arrancó un dedo de un mordisco con la intención de llevárselo como reliquia. Cuando, ya fuera de la iglesia, el séquito real pretendió cruzar el río Manzanares, el caudal de éste creció de tal manera que resultaba totalmente imposible vadearlo, situación que se prolongó hasta que la susodicha dama confesó su acción y devolvió al santo el dedo amputado. La anécdota, muy similar a la que le sucediera a la esposa de Alfonso XI, tiene el mismo mensaje: San Isidro quiere ser madrileño y no consiente que su cadáver incorrupto, centro del culto, sea desmembrado y dispersado. Pero, a pesar de estos milagros-castigo, su prestigio como mediador para la obtención de lluvias, extendido a las comarcas próximas, provocó las reivindicaciones de otras localidades. Así, tal y como quedó recogido en las Relaciones Topográficas de Felipe II, tanto Uceda como Mesones (ambos lugares en la actual provincia de Guadalajara) afirmaron tener reliquias del santo labrador (su cabeza) en sus respectivas iglesias (Christian 1991: 162-163).

También del siglo XV datan las primeras ordenanzas conocidas de la cofradía de San Isidro, fechadas en 1487, que se nombran como las segundas (Cuartero y Huerta 1967: 92-93) (debieron existir unos estatutos desde el momento de su fundación a finales del xiII). La cofradía se unió a la del Santísimo Sacramento de la parroquia de San Andrés el 12 de marzo de 1537 (García Villada 1922: 84) y sus ordenanzas fueron confirmadas canónicamente en 1557 por Juan Martínez Silíceo, arzobispo de Toledo.

Su estructura es similar a la de otras de la época estableciendo las normas de la vida corporativa, la celebración y participación de sus miembros en las fiestas y los aspectos de mutuo apoyo y solidaridad entre los hermanos, frente a la enfermedad, viudedad, orfandad, muerte u otras desgraciadas contingencias como ser hecho prisionero. Pero si las comparamos con las normativas de instituciones similares coetáneas y vigentes en pequeñas localidades, encontramos algunas variantes significativas; especialmente el gran desarrollo e importancia que se da a la gestión de todos los asuntos económicos que ocupan buena parte de los estatutos, mostrando con claridad que la mayoría de los cofrades no son pobres 
campesinos, sino acaudalados caballeros madrileños, probablemente muchos de ellos ligados a la tierra como terratenientes; lo que en algunas fuentes como los Libros de Acuerdos del Concejo Madrileño, se denominan "labradores". Son ellos quienes encuentran en el santo un fiel siervo, y su propia clase social será a partir de este momento la principal beneficiaria de los milagros.

Entre ellos es obligado reiterar el protagonismo del linaje de los Vargas, el cual a través de Francisco de Vargas, jurisconsulto del emperador Carlos $\mathrm{V}$, en 1518, pide y obtiene de Roma permiso para erigir una capilla decente al santo en territorio del antiguo cementerio de San Andrés que, a la vez, se convertiría en panteón familiar (Matilla Tascón 1985: 32). Se trata de la que se conocerá como la "capilla del Obispo" por terminarse las obras con su hijo, Gutierre de Vargas Carvajal, obispo de Palencia. Allí descansó el sagrado cuerpo desde 1535 hasta que en 1555 regresó a su emplazamiento originario tras ganar la parroquia la disputa canónica que mantenía con esta familia. Todavía en otra ocasión, cuando en 1669 se hundió la iglesia de San Andrés, Isidro fue alojado en la capilla del Obispo hasta su reconstrucción.

Para lograr el primer traslado de la reliquia, el linaje de los Vargas

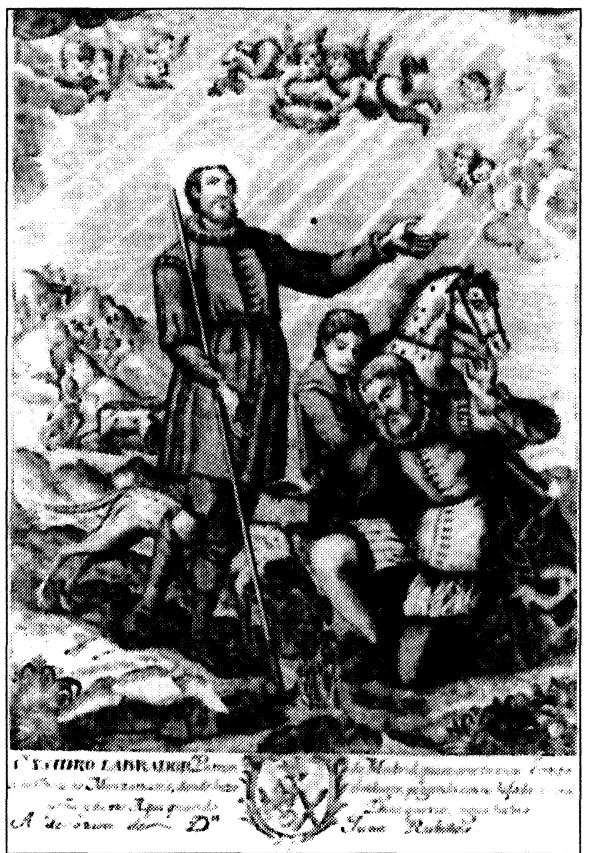

Figura 8.-Estampa de San Isidro ofrecida por un cofrade. Siglo XVIII, Museo Municipal de Madrid. que desde al menos un siglo antes mantenía una vinculación con el santo y su cuerpo, adujo que éste fue siervo de un antepasado, Iván Vargas, en cuya casa vivió obrando algunos milagros que le beneficiaron, tales como la resurrección de su caballo, también la de su hija y sobre todo, el más renombrado, hacer brotar un manantial para calmar la sed del caballero, cuando trabajaba en sus tierras. Del santo del siglo XII que se enfrentaba a su amo dedicando el tiempo de trabajo a la oración, al que aparece ahora haciendo milagros tan sólo por procurar su bienestar, se ha producido una transformación radical y difícil de conjugar. Conviene advertir también que se está alterando el contenido del Códice medieval, donde se precisa que Isi- 
dro no vivió en casa de su amo ni fue un siervo, sino un aparcero instalado en una alquería con su mujer, en los campos del propietario, cultivándolos por una porción del territorio o la cosecha; lo que las fuentes medievales denominan quinteros, que era la modalidad de trabajo más extendida en la Comunidad de Villa y Tierra de Madrid.

Pero debemos detenernos un poco más en este manantial que al parecer era de aguas milagrosas, especialmente indicadas para curar las calenturas y del que hasta ahora no habíamos tenido noticia. En Madrid, asentada sobre un inmenso acuífero, no faltaban fuentes milagrosas o con propiedades medicinales; por la misma época, se documentaban también otras linfas a las que se atribuían estas propiedades como la de Santa Polonia, la Fuente Santa o el pozo de la beata Mariana, además de varias más, consideradas medicinales en Lavapiés, en el Prado Viejo, Carabanchel y la Casa de Campo (Fernández Montes 1994: 133). Evidentemente se acudiría a ellas como un recurso extendido a todas las capas sociales en una sociedad en la que medicina, magia y religión frecuentemente se confundían y entremezclaban, siendo difícil trazar las fronteras entre unas y otras. La de San Isidro, según el testimonio de Jerónimo de Quintana, vertido en su Historia de Madrid, (1629: 305) tan sólo se secó una vez en 1575, porque los moros vendían el agua. Esta noticia no debe sorprendernos, dado que entre los musulmanes también existen numerosos manantiales y fuentes milagrosas originadas por santos y, además, vuelve a incidir en la huella islámica que tanto Madrid como su patrón dejaron traslucir durante siglos, después de la conquista cristiana. Al asociarse al culto un manantial de aguas con efectos curativos, se obtuvieron varios e importantes beneficios para su consolidación y extensión. Por una parte, se fundamenta la reivindicación de la familia de los Vargas como descendientes del amo de San Isidro y por tanto legítimos custodiadores de su cadáver en la capilla del Obispo. En la misma línea se acrecienta el carácter del santo como el mejor de los siervos posibles, hasta el punto de obrar un milagro "para calmar la sed de su amo" que no se encontraba en el desierto ni en una situación extrema, sino en una villa asentada sobre un acuífero, llena de fuentes y manantiales a escasa distancia. Por esta causa los caballeros y nobles, los principales miembros de la cofradía fundada bajo su patronazgo, pueden quedar satisfechos y deseosos de impulsar y potenciar al patrono local. Pero por otra parte, al existir una fuente milagrosa se posibilita la extensión de la devoción a las clases populares que acuden a beber del agua bendita, abriéndose una puerta a las romerías y peregrinaciones hacia este nuevo enclave de carácter rústico. El culto cuenta ya con dos focos, uno dentro del recinto urbano (el cuerpo incorrupto en la iglesia de San Andrés) y otro a las afueras. Se 
obtiene así la dualidad ciudad-campo que tanto ha gustado a la religiosidad popular. Los devotos se dirigen a la pradera de San Isidro para sanar bebiendo de la fuente, pero también van al interior de la villa, donde está el sepulcro, en demanda de lluvias.

Junto al manantial se erigió una ermita que, según la tradición, fue mandada edificar en 1538 por la mujer de Carlos V, en agradecimiento al santo por haber sanado de tercianas a su marido y a su hijo Felipe II cuando éste aún era niño, tras beber en el lugar. Si esto fuera cierto ${ }^{7}$, verdaderamente, Isidro, al poner su capacidad taumatúrgica al servicio de la monarquía, jugó una gran baza a favor del futuro de Madrid y de su propio destino dentro del santoral. No sólo se granjeó el apoyo de Carlos $\mathrm{V}$ a la Villa que fue impulsada con exenciones y franquicias, sino sobre todo, con Felipe II, ésta se convertirá en la sede de la Corte en 1561, siendo la salubridad del emplazamiento madrileño y la bondad y abundancia de sus aguas algunas de las razones que tradicionalmente se han aducido para justificar esta decisión. Además, las propiedades curativas atribuidas a este manantial que se especializa en las calenturas, sobre todo tercianas y cuartanas, informan de las principales enfermedades de la sociedad madrileña del siglo XVI, donde, tras las pestes que asolaron toda Europa, las calenturas y fiebres producidas por procesos infecciosos son la primera causa de preocupación, y así quedó reflejado en las Relaciones Topográficas de Felipe II (Alvar 1993) en múltiples localidades castellanas.

Como indicara Gómez Iglesias (1962: 39), el apego y las largas estancias en Madrid de los Reyes Católicos, Carlos V y Felipe II que conllevaron la instalación en la Villa de muchos nobles y eclesiásticos de gran influencia y poder, como el linaje de los Mendoza o el Cardenal Cisneros, hicieron del lugar la sede de la corte de una forma natural y paulatina, anterior a 1561, cuando Felipe II la asienta de forma explícita.

Por las mismas fechas (1545-1563) se estaba celebrando el Concilio de Trento, como respuesta a la Reforma protestante protagonizada por Lutero quien, entre otras cosas, atacó directamente el culto a los santos medievales, acusando, no sin razón, de falta de rigor histórico en las hagiografías y de su caprichosa proliferación en villas y ciudades. Consecuentemente, también se pone en tela de juicio el esperpéntico tráfico de reliquias, con sus inevitables falsificaciones, las disputas por su custodia y en definitiva, la visión folklórica del culto que rozaba la superstición y

\footnotetext{
7 Como ya indicó Matilde Verdú (1986: 33) existe documentación probando que la ermita primitiva fue edificada por la Cofradía del Santísimo Sacramento y San Isidro, que se había fundado como unión de las dos anteriores en 1537.
} 
la magia. La Contrarreforma se afirmó en la veneración a los santos y sus reliquias, pero se inició una revisión eliminándose muchos de ellos del santoral e insistiéndose en la necesidad de verificar la autenticidad de las reliquias y de reservar al papa las canonizaciones (Caro Baroja 1978: 79-80).

Las hagiografías que, como la de San Isidro, se fundamentan en la tradición oral son el objetivo prioritario de esta depuración, que le afectará muy directamente. Así, en 1567, el gobernador y administrador general del arzobispado de Toledo visita las reliquias pero sin ningún tipo de solemnidad y con las puertas de la iglesia de San Andrés cerradas, por no estar el santo canonizado. Más rigurosas y específicas son las normas dictadas en 1570 por el doctor Gencor, que prohibe sacar el cuerpo de su sepulcro para mostrarlo al público, incluyendo penas de excomunión para el cura y el beneficiado de la iglesia si incumplían el precepto (Fernández Villa 1987: 70-71). Aunque el culto no se interrumpió totalmente, la reliquia no volvió a salir a la luz, ni fue expuesta ante los devotos. En el último cuarto del siglo xvI, tan sólo en tres ocasiones se abrió el sarcófago y esto se hizo de forma privada para que lo contemplaran algunas autoridades diocesanas y cortesanos destacados (Río Barredo 1997: 111). Isidro, aquel personaje legendario al que nobleza y clero elevaron hasta los altares durante la Edad Media, estaba seriamente dañado, precisamente en el momento en que Madrid, convertida en la sede de la Corte, podía aspirar a una advocación a la altura de su creciente importancia.

\section{LA PREPARACIÓN DE ISIDRO LABRADOR PARA SU CANONIZACIÓN}

La obtención de una canonización otorgada por el papa era, sobre todo, una cuestión de poderes e influencias. Los requisitos de santidad, teóricamente endurecidos y depurados tras la Reforma tridentina, se doblegaban ante determinados intereses de la cristiandad. Así, como tan irónicamente expuso Aviad M. Kleinberg (1984: 13), para alcanzar este estado era necesario que Roma sintiera "simpatía por la causa"; no era imprescindible que el aspirante fuera rey, noble, benefactor de una gran ciudad o fundador de una orden monástica, ni tampoco ser compatriota de la máxima autoridad eclesiástica, pertenecer a su familia o a la de algún personaje político o religioso de peso en Europa, pero cualquiera de estas circunstancias ayudaba de forma mucho más decisiva que las virtudes y milagros del candidato.

Felipe II, autoproclamado defensor de la cristiandad, que enroló a todo su reino en las guerras religiosas, por una parte se encontraba en esa 
posición de poder e influencia ante Roma y por otra, al apostar por Madrid, también lo hacía por su patrón y benefactor; a Isidro le había llegado su oportunidad casi cuatro siglos después de que se iniciara su culto. Así, a instancias de la Cofradía de San Isidro y el Santísimo Sacramento cuyos miembros pertenecían a la influyente oligarquía urbana, en 1593 el monarca escribe al papa Clemente VIII para solicitar la canonización, respaldado no sólo por los cofrades sino también, y de manera unánime, por las órdenes y clérigos madrileños, además del apoyo entusiasta del Concejo de la Villa, monopolizado por las élites urbanas, que se hizo cargo de todos los gastos del proceso. María José del Río (1997: 113) apoyándose en un artículo de J. Tazbir que no hemos podido consultar $^{8}$, afirma que la clases dominantes madrileñas, especialmente los caballeros, pusieron muchas reticencias a que un humilde labrador fuera nombrado patrón y hubieran preferido, tal vez, otras alternativas como Santa Ana, cuya festividad se celebraba en la villa. No hemos encontrado ningún testimonio que confirme esta afirmación, mientras por el contrario son múltiples las manifestaciones y acciones de apoyo por parte de los más destacados miembros de la sociedad madrileña que, como ya hemos dicho, encuentran en el personaje el siervo perfecto al servicio de sus intereses. Además, frente a la mencionada Santa Ana, aún sin estar canonizado ni ser comparable en importancia dentro del santoral, el humilde labrador presentaba bastantes ventajas. Parece razonable suponer que la abuela de Jesucristo tendría mayor capacidad mediadora ante Dios, pero lo cierto es que su culto, junto al de San Roque, se había extendido por toda Europa tras las epidemias de peste del siglo XIV y eran muchísimas las localidades que la invocaban o habían ofrecido votos, teniendo que repartir entre todas ellas sus intercesiones. Por el contrario, la veneración a Isidro estaba limitada a la villa y las comarcas agrícolas próximas, concentrándose aquí todo su poder taumatúrgico. Pero, sobre todo, mientras que de Santa Ana tan siquiera se poseían las cuestionadas reliquias, del campesino madrileño se conservaba entero el cadáver incorrupto, foco por antonomasia de todos los actos y celebraciones en los cultos europeos.

Felipe II encargó todos los trámites de la canonización a Fray Domingo de Mendoza, nombre que conviene recordar y tener bien presente, pues, actuando como un auténtico profesional, le debemos no sólo el éxito de todo el proceso, sino sobre todo la minuciosa remodelación del personaje, ajustando y transformando su hagiografía en consonancia con el modelo de santidad vigente en la época; es el San Isidro que en gran

${ }^{8}$ TAZBIR, J. 1975. "The Cult of St. Isidore the Farmer in Europe", en Poland at the 14th. International Congress of Historical Sciences. San Francisco. 
medida ha llegado hasta nuestros días. No vamos a detenernos en los tortuosos y dilatados procesos burocráticos —que se prologaron durante treinta años, hasta la beatificación en 1619 por Paulo V, siendo por fin canonizado en 1622, con Gregorio V, durante el reinado de Felipe IV-, ya que el tema ha sido ampliamente tratado por Nicolás Sanz Martínez (1983) y Antonio Matilla Tascón (1983) entre otros. Pero sí detallaremos lo que desde nuestro punto de vista resulta mucho más interesante, es decir: las alteraciones y adicciones que sufre el personaje y los cauces utilizados para la difusión de su culto.

Aunque para los madrileños y agricultores próximos, Isidro Labrador fuera reconocido como santo patrón, lo cierto es que, al no estar canonizado, había quedado excluido de todas las recopilaciones y relatos de vidas de santos, no contando con otro testimonio que el viejo y nada difundido códice de finales del siglo xiII, escrito en latín y una traducción del mismo, realizada por Juan Hurtado de Mendoza en 1560 . El género hagiográfico había cambiado radicalmente en la época renacentista. Durante la Edad Media, los escritores de biografías sagradas las conciben como relatos destinados a ser leídos o recitados ante un público analfabeto y utilizan por tanto múltiples recursos orales y teatrales, como su frecuente formato en verso, la brevedad y viveza plástica de las narraciones o los elementos teatrales. A esto se unía la total falta de depuración del santoral y la admisión de cualquier tipo de relato o milagro por inverosímil, incluso grotesco que pudiera resultar. Pero en el Renacimiento este modelo empieza a entrar en crisis y los repertorios tradicionales son cuestionados, siendo un ejemplo emblemático La Leyenda Dorada de Jacobo de la Vorágine que causó auténtico furor durante la Edad Media y de la que Vicens Vives, en un duro ataque a la obra, llegará a decir que no es de oro, sino de hierro oxidado (Birge Vitz 1991: 97-110-111). Paralelamente, en los siglos XVI y XVII asistimos a la proliferación de los flos sanctorum, voluminosísimas obras destinadas a una lectura privada por miembros de las clases pudientes que ya están alfabetizadas e incorporan a sus bibliotecas estas obras piadosas. Así, las vidas de santos, escritas ahora en prosa y en la lengua vernácula, se hacen mucho más extensas y pesadas, cambiando su primitiva agilidad y frescura por largas disgresiones, a la vez que se añaden todo tipo de detalles y descripciones (Birge Vitz 1991: 97-114). En España los flos sanctorum tuvieron una rápida aceptación y proliferación, destacando por su éxito entre el público de la época el de Alonso Villegas, con una primera impresión en 1565, y el de Ribadeneyra, de 1599. Pero la difusión popular del género no se interrumpió y en la Península los ciegos y otros profesionales contribuyen a su popularización a través de las aleluyas y pliegos de cordel que 
recitarán en las plazas de villas y pueblos. Paralelamente también aparecen las comedias de santos que serán un importante vehículo de difusión hagiográfica.

El inteligente Fray Domingo de Mendoza, dispuesto a extender el conocimiento del santo Labrador, encarga sendas biografías a dos madrileños destinados a alcanzar las más altas cotas de prestigio y popularidad dentro de su género. Una, a Alonso de Villegas, el más afamado de los hagiógrafos de la época cuyo flos sanctorum tuvo múltiples ediciones en los siglos XVI, XVII y xVIII (VILLEGAS 1787), aunque lógicamente hasta la canonización no incluye la vida de Isidro. La otra, destinada a la difusión, es solicitada a un joven de 19 años, Lope de Vega, a quien se especifica que la composición debe ser en verso para su más fácil memorización y difusión. Ambos autores reclaman al dominico el manuscrito original para poder realizar su versión, pero Lope de Vega lo recibe varios años después, tiempo durante el cual no escribe su obra. Como disculpa por la demora -se conserva la correspondencia que se cruzaron (Lope de Vega 1599: 272) — el fraile alega sus múltiples ocupaciones, pero también se podría pensar que tenía interés en que, antes de que empezara a circular la versión de Lope, ya estuviera publicada "la oficial", compuesta por un especialista en el género. Y efectivamente, Alonso de Villegas dedica a Isidro una hagiografía individual: Vida de Isidro Labrador, cuyo cuerpo está en la Yglesia Parroquial de S. Andrés de Madrid, publicada en 1592, en la que, con la prudencia que exigía el proceso de canonización en trámite, no se tilda a Isidro de santo. Poco después Fray Juan Ortiz Lucio, siguiendo el contenido de esta obra, trata la vida del patrón madrileño en su flos, publicado en 1597, mientras que el propio Villegas añadirá este relato en su Santoral Extravagante (Martínez Arancón 1978: 403-421), apéndice dedicado a los individuos no canonizados, pero popularmente reconocidos como tales. Tras obtener el beneplácito papal en 1622, la vida de San Isidro formará parte de las ediciones posteriores, no sólo de su compendio hagiográfico, sino que, copiada de forma prácticamente literal, aparecerá también en el de Ribadeneyra (1688 II: 81-89).

Mientras, la biografía de Lope de Vega, que no saldrá a la luz hasta 1599 con el también cauto título de Isidro. Poema castellano, cumple su función alcanzando una enorme popularidad, con reimpresiones en 1602, 1603, 1608, 1613 y 1638 (García Villada 1922: 115). Se constituyó en la fuente de inspiración de los pliegos de cordel dedicados al santo que muy pronto, extractando algunos párrafos del poema, empezarán a difundirse. Sirva de ejemplo el localizado por María Cruz García de Enterría en la Brithish Lybrary de Londres, fechado en 1606 (García de Enterría 1977: 56.) Pero Lope de Vega (1964: 393-443), convertido en paladín entusiasta de 
la causa, no es capaz de esperar al reconocimiento papal y en 1617 estrena una deliciosa comedia: San Isidro Labrador de Madrid, que difundirá la vida del santo entre las clases medias madrileñas. Además, escribió otras dos piezas teatrales: La niñez de san Isidro y La juventud de san Isidro (Lope de Vega 1964: 325-360 y 361-392), representadas durante las fiestas celebradas en Madrid con motivo de su canonización; organizó y participó (bajo el seudónimo de Maestro de Burguillos) en la Justa poética, completando su labor con la Relación de las fiestas (Lope de Vega 1777).

\section{Las reliquias de San Isidro y Santa Maria de la Cabeza}

Más adelante nos extenderemos en el comentario de estas obras, pero antes nos parece de interés abrir un pequeño paréntesis para tratar de un tema que, aunque algo escabroso, es inseparable de la vida de los santos en los siglos XVI y XVII. Nos referimos a sus reliquias. El códice medieval que narra la aparición del cuerpo incorrupto, acaecida en 1212, contiene dos menciones de las que se podría deducir que Madrid había escogido como benefactor a un hombre de pequeño tamaño. Así tras narrar su muerte, se puede leer: "hoy su pequeño pero glorioso cuerpo descansa entre los apóstoles" (Anónimo 1993: 121). Asimismo, antes hemos reproducido un milagro que describe una rogativa en la que sacan el "cuerpecillo" del santo de su arca para colocarlo a los pies de la imagen de la Virgen de Atocha. Durante el siglo XIII Isidro salió del sepulcro con bastante frecuencia y los devotos pudieron no sólo contemplarlo, sino ocasionalmente tocarlo o frotarse con su sudario, en demanda de los milagros que se producían al contacto con la sagrada reliquia. Las aperturas parece que se interrumpieron, o al menos no han quedado reflejadas en los siglos XIV y $\mathrm{xV}$; sólo sabemos de dos casos: en 1344, la llamada exhumación del cuerpo de San Isidro y en 1421, la apertura y reconocimiento del cadáver, reflejada al final del Códice. En ninguno de estos documentos se hacen menciones que puedan hacernos atisbar alguna característica del cuerpo. Sin embargo en el siglo XVI, el arca se empieza a abrir con relativa frecuencia: en 1504, el Cardenal Cisneros, dispuesto a difundir el culto entre el pueblo, comisiona al arcipreste de Maqueda, el cual no sólo abre el sepulcro sino que lo deja así durante nueve días expuesto ante los devotos y describiéndolo de la siguiente manera:

[...] envuelto en un paño como de tafetán blanco e cubierto con una como colcha de colores, en lo cual está el dicho cuerpo santo entero, en hueso y carne, salvo el brazo derecho despegado del cuerpo, que dicen que le hizo despegar la reina Doña Juana. Es de grande estatura (García de Villada 1922: 22). 
Queremos destacar que en esta ocasión se dice que "es de grande estatura" y que tiene un brazo arrancado. Por las mismas fechas, el tan poco fiable, Lucio Marinero Sículo incluye la vida de San Isidro, con una descripción de su cuerpo, en De rebus Hispaniae Memorabilibus, editada por primera vez en 1496-97 y notablemente ampliada en 1530 (Caro Baroja 1992: 91-92); su versión será una de las fuentes no sólo de los hagiógrafos posteriores, sino también de los compositores de los pliegos de cordel. La descripción que realizó sobre el estado de la sagrada reliquia fue reproducida por Alonso de Villegas y Rivadeneyra:

Es un continuo milagro la incorrupción del cuerpo de S. Isidro, y el suave olor, que echa de sí, muy diferente de todos los olores, que produce la naturaleza, y que puede componer el arte. Marineo Sículo dice estas palabras: Yo he visto su santo cuerpo, y está tan entero, que no parece sino que ha dos, o tres meses, que murió; y lo que admira es, que en cualquier cuerpo lo primero que empieza a faltar, es la punta de la nariz, y los blancos de los ojos: esto tiene tan entero que admira (Martínez Arancón 1987: 420-421).

No cabe duda de que el cuerpo que se exhibe a principios del XVI, es el de un hombre grande en notable buen estado de conservación. La contradicción con los datos del códice primitivo no supuso ningún tipo de obstáculo, ya que este manuscrito era totalmente desconocido en la época. Ante el agrandamiento del originariamente tildado como "cuerpecillo", desechadas las explicaciones científicas, sólo nos quedan dos alternativas: una es su crecimiento milagroso, no apuntado jamás por ningún autor y la otra, lo que vulgarmente se podría denominar el "cambiazo". Es posible, incluso probable, que el arcipreste de Maqueda, por decisión propia o inducido por el Cardenal Cisneros, a la hora de exhibir ante el público la sagrada reliquia incorrupta, no tuviera reparos en presentar una que "diera la talla" tanto por su estado de conservación, como literalmente hablando. $\mathrm{Y}$ es que entre los atributos de los héroes $-\mathrm{y}$ un santo al fin y al cabo no es más que un héroe del cristianismo- está su gran tamaño, uniéndose así su superioridad física a la moral.

En 1593 los comisionados para promover la canonización no sólo abren el arca sino que realizan detalladísimos informes sobre su estado para incluirlos en los documentos que se enviarán a Roma:

[...] un cuerpo entero de hombre, de grande estatura, el cual está muy decentemente puesto, y envuelto en una como sábana de tafetán blanco y una almohada debajo de la cabeza del mismo tafetán, llena de estopas, sin que la dicha sábana y almohada tuviese corrupción alguna; y el cuerpo estaba entero, y las manos y brazos cruzados sobre el vientre, y todo el cuerpo, excepto brazos y piernas y pies y manos y cabeza, estaba con su cuero natural, aunque seco [...] 
aunque el cuero de la cabeza estaba gastado, pero las cuencas de los ojos no estaban vacías, como suelen estar las calaveras de otros difuntos [...] y notó que en la sien izquierda tenía otro poco de carne que no se había comido; pero todos los miembros de pies y piernas, manos y brazos los tenía enteros, sin que le faltase hueso ninguno, salvo que, como tiene dicho, en estos miembros de pies y de manos y brazos le parece que no tenía cuero. Y vió que estaba dentro de una bolsita un hueso que, al parecer de los que allí se hallaron y de este testigo, era de un dedo pulgar de un pie; [...] y dentro de la caja interior [...] al lado izquierdo había un palo basto, que a su parecer, es de roble o acebo, el cual decían que servía al santo de aguijada cuando iba arando con los bueyes; y el dicho palo vió que estaba por algunas partes cortada la corteza, lo cual decían todos públicamente que algunas personas devotas lo habían sacado por reliquias (García Villada 1922: 25).

A finales del XVI, el cuerpo parece algo más deteriorado que en las descripciones de principios del mismo siglo, nuevamente se vuelve a destacar su gran estatura y en vez de mencionarse el brazo arrancado por la reina Juana, se habla aquí del dedo que de un mordisco desprendió la dama de Isabel la Católica. Pero además, acompañando el cadáver aparece un elemento del que hasta ahora no habíamos tenido mención alguna y que a partir de este momento, se unirá de forma indisoluble a la iconografía isidriana, nos referimos a su famosa aguijada. La vara, el palo, ha desempeñado diversas funciones en las culturas humanas como ya señaló Radcliffe-Brown; desde su humilde uso como útil agrícola o ganadero, a su función simbólica dentro de la sociedad, normalmente ligada a la ostentación del poder y la dignidad por la más alta jerarquía; el cetro, el bastón de mando de reyes, alcaldes, militares, etc. Esta simbología tiene orígenes muy antiguos, documentándose ya entre los persas, los egipcios o en el Antiguo Testamento. El palo es un símbolo de la autoridad, también del árbol, visto como divinidad silvestre, y por ello acompaña a sacerdotes y reyes en sus representaciones.

Pero además, su ligazón a los santos y su capacidad taumatúrgica como "varita mágica", a través de la cual se transmite el poder de su propietario, también tiene antiquísimos precedentes, baste recordar su utilización por Moisés para abrir un camino seco en el río Nilo, cuando huía con su pueblo de Egipto. Entre los musulmanes el bastón del santo en que se apoyaba al caminar, queda impregnado de su baraka y se clava sobre su tumba, indicándose

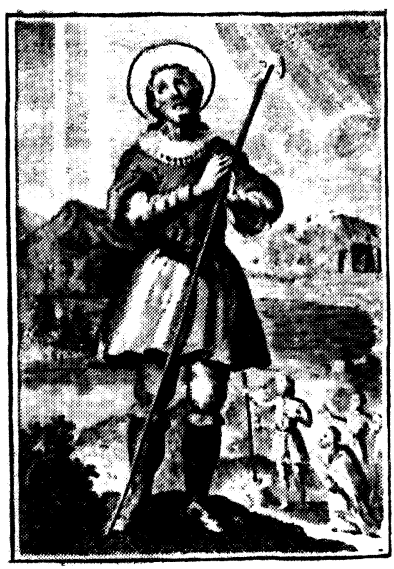

FIGURA 9.-San Isidro. Museo Municipal de Madrid. 
así la condición del difunto; es como un fetiche que absorbe su virtud milagrosa y representa ante el público la gracia de sus dones (Arqués 1953: 41 y 151-153). Ya comentamos que San Isidro empleó su aguijada para hacer brotar el manantial de su nombre según la versión de este milagro, difundida en el siglo Xv. Pero será a partir del XVI cuando su empleo se extienda y generalice a otros muchos prodigios, prácticamente todos ellos relacionados con la obtención de agua, algunos acaecidos en el contexto urbano madrileño, dentro del cual no resulta muy coherente vagar con una aguijada, si no es precisamente por sus propiedades mágico-milagrosas. En este sentido también los zahoríes emplean una vara para averiguar el paradero de las aguas subterráneas $\mathrm{y}$, como veremos luego, se establecerá un paralelismo entre el patrón madrileño y éstos individuos que reforzará su carácter como santo. Además ese palo, al situarse dentro del arca junto al cuerpo, cobra carácter sagrado y mientras de los restos humanos no se deben desprender porciones, pues se provoca un milagro-castigo, al parecer, la aguijada sí puede ser descortezada y mutilada por los devotos que obtienen así las codiciadas reliquias.

En resumen, durante el siglo $\mathrm{xv}$, el cuerpo incorrupto de San Isidro sufre una serie de transformaciones, tanto en su tamaño como en su ajuar, ajustándose al modelo del héroe taumaturgo de gran tamaño y acompañado de su vara prodigiosa, lo que sin duda facilitará el reconocimiento de su condición y la extensión del culto.

Más rocambolesco todavía resulta el relato de la aparición de las reliquias de su mujer. Como recordaremos, según el Códice, de finales del XIII (que no es una biografía sino tan sólo el relato de cinco milagros), Isidro fue un campesino casado y con un hijo. De su esposa tan sólo se menciona que asistió como testigo a la multiplicación de alimentos para asistir a un pobre y acompañó al santo en el momento de su muerte. Como una auténtica santa se limitó a obedecer, callar, tratar de agradar a su marido y contar posteriormente sus prodigios al vecindario. Es un personaje tan secundario y humilde que ni siquiera se menciona su nombre. Pero ahora resultaba de interés prioritario llenar del contenido adecuado ese matrimonio, a la vez que se dotaba de personalidad a la oscura esposa anónima. Así, a partir de 1596, el propio Fray Domingo de Mendoza emprende diligencias para averiguar algo sobre su vida, a la vez que indaga el paradero de su cuerpo (Quintana 1629: 330-332).

Habían pasado cuatro siglos desde la exhumación de Isidro, originariamente enterrado en el cementerio de San Andrés, por lo que resultaba prácticamente imposible justificar la aparición de los restos de su mujer en el lugar, pues simplemente éste había desaparecido incluyéndose dentro de la iglesia y también era de muy difícil verosimilitud su hallazgo en el 
recinto de la villa. Según el Padre Bleda, que escribió una hagiografía basada en el Códice de Juan Diácono pero con "adiciones" propias en 1622, la mujer de San Isidro, Santa María de la Cabeza, que no sólo tiene ya nombre, sino que además es denominada santa, tras la muerte de su marido, se retira a Caraquiz para dedicarse por completo al cuidado de la ermita que desde años antes tenía a su cargo. Para Fidel Fita se trataba de la ermita de Nuestra Señora de Belvis, situada en la Peña Rasa, llamada antiguamente Erraza, es decir Cabeza en árabe y en donde existía una alquería, propiedad de la familia Vargas (Fita 1886 a: 416). Allí muere, siendo enterrada dentro la ermita de Nuestra Señora de la Cabeza. Después de unos años, para que no fueran expoliadas las reliquias, se saca el cuerpo y se esconde en los cimientos de la sacristía, dejando tan sólo la cabeza en el altar mayor. Aquí aparece una curiosa coincidencia y para algunos el apelativo "de la Cabeza" procede del nombre de la peña Erraza, vinculándose así, también a la esposa del labrador madrileño con las propiedades y los siervos del linaje de los Vargas; mientras que para otros, es esta calavera la que le da el sobrenombre, siendo por ello invocada como abogada contra los dolores de cabeza. Sea como fuere, el caso es que, según los relatos de la época, con el paso del tiempo se olvida la identidad del sujeto al que pertenecía la reliquia, hasta que en 1596, la esposa de San Isidro se aparece durante la noche al propio Fray Domingo de Mendoza y le dice dónde están los restos de su cuerpo. Allí acude el fraile con toda una compañía de religiosos y laicos que lo desentierran, percibiendo el característico e indicativo olor a santidad. Los médicos que también han acudido al evento, unen los restos a la cabeza y certifican que pertenecen a la misma persona; nadie duda de que se trata de la esposa de San Isidro, fallecida en el siglo XII. Tras este prodigio, todas sus reliquias son depositadas en el convento de la Madre de Dios de la Orden de San Francisco en Torrelaguna, aunque, tras la canonización de su marido, la cabeza de Santa María de la Cabeza se traslada a Madrid para que reposen juntos los restos del matrimonio, siendo también los de ella sacados frecuentemente en procesiones y rogativas.

\section{La bagiografia de Alonso de Villegas}

Los miembros de la cofradía de San Isidro con el poderoso linaje de los Vargas a su frente presionando por el reconocimiento papal; el Concejo madrileño que corrió con todos los gastos del proceso de canonización; la inclusión del personaje en las historias de España de algunos falsos cronicones; la biografía de Alonso de Villegas, que recogió y aunó en un 
relato coherente todas las noticias previas a su publicación; las obras de Lope de Vega que devolvieron el personaje a las clases populares; el Cabildo madrileño de religiosos y los poderes eclesiásticos apoyando y materializando los deseos de la monarquía; Carlos V y Felipe II que no dudan en reconocerse como beneficiarios de sus milagros e iniciar las gestiones que posibilitarían el reconocimiento papal. Muchas personas e instituciones parecen haber colaborado en la recreación de San Isidro a finales del XVI, pero ¿a cuál o cuáles de ellas se debe la caracterización renacentista del personaje?

Repasando las fechas de publicaciones, hallazgos y nuevos milagros pensamos que en realidad se trató de una labor de equipo, dirigida por los poderosos Vargas, tan cercanos a los monarcas, además de miembros de la cofradía, y hábilmente conducida por fray Domingo de Mendoza que sin duda contó con la colaboración y complicidad de Alonso de Villegas, en cuyo relato encontramos ya todos los elementos claves que caracterizarán al nuevo personaje.

Como ya hemos mencionado, el renombrado Alonso de Villegas, aunque no pudo incluir al patrón de Madrid en su flos por no estar canonizado, a instancias de Domingo de Mendoza, le dedicó una biografía individual, aparecida en 1592. En ella se sigue un método muy practicado por los hagiógrafos de la época, consistente en que, por una parte, se cita y sigue con frases textuales el manuscrito original, pero, simultáneamente se introducen pequeñas variantes en los textos para acomodarlos a la época, además de intercalarse nuevos milagros y episodios. Como fuentes de información cita en primer lugar a Juan Diácono (Martínez Arancón 1978: 406), es decir el autor del primer códice que sin lugar a dudas es la guía que conduce toda su narración, aunque el resultado final difiera bastante. Si este manuscrito, con una imprecisión absoluta y la declaración inicial de que lo narrado se basa en la tradición oral, no tiene ningún valor desde el punto de vista histórico, los dos autores en que se refuerza, hoy en día han quedado totalmente descalificados. Uno de ellos es Juliano, compositor de un falso cronicón, quien, sin ningún reparo, sitúa la muerte de Isidro Labrador el 28 de noviembre de 973 (Martínez Arancón 1978: 417), fecha absolutamente inverosímil e incompatible con los datos del manuscrito primitivo, según el cual, el óbito debió producirse a finales del siglo XII. El otro es Lucio Marineo Sículo, quien en su Historia de España incluyó la descripción del cuerpo del santo que reprodujimos más arriba, junto con otras muchas noticias seudohistóricas, tomadas de los falsos cronicones.

Las modificaciones introducidas en los cinco milagros primitivos, con fina sutileza, producen cambios decisivos. En primer lugar destaca que, 
cuando se menciona al amo, éste ya tiene nombre: Iván Vargas, es decir el que este linaje había impuesto para reivindicar que el santo fue siervo de uno de sus antepasados. Además, el enfrentamiento entre éste e Isidro, cuando el último dedica parte de su jornada laboral a la oración, se suaviza bastante. En el milagro de los bueyes arando, fiel al Códice, Iván no ve ángeles guiando los bueyes, sino sólo a las bestias, pero cuando pregunta y el santo niega la ayuda humana, el amo comprende que eran éstos seres quienes le ayudaban. Cuando multiplica los alimentos de una olla para alimentar a un pobre que se acercó a mendigar a su casa, el último se identifica con Jesús, cristianizándose así este comportamiento que podría haber tenido su origen en la tradicional hospitalidad islámica. Por otra parte al narrarse que el santo permaneció orando en santa María Magdalena, mientras un lobo atacaba a su burro, se añade que la iglesia se hallaba en Carabanchel de Abajo, para ajustarse a los establecimientos existentes en el siglo XVI. La mención a esta advocación es suprimida sin embargo del último milagro, cuando multiplicó la comida tras el banquete de una cofradía para alimentar a unos pobres, sin duda porque el momento de difusión de este culto se produjo a finales del xiII y ahora ya no resulta tan interesante presentar al personaje como su más fiel devoto.

En el relato original, Isidro acudía a las iglesias a rezar, pero ahora lo que hace es ir a misa, y con esta modificación se producen nuevos episodios, como cuando los bueyes aran solos mientras él permanece en la liturgia, o la escucha en éxtasis, en una ocasión en que no pudo asistir personalmente.

El milagro de las palomas, cuando en invierno las alimentó con el grano destinado a cubrir sus necesidades y tras la molienda se multiplicó la harina, dará lugar a variantes de interés. Una es que el suceso se produce durante la siembra y los animales alimentados son pájaros y hormigas a los que también en ocasiones se añaden los pobres, lo que -como ya señaló Joseph Nicolás de la Cruz (1790) y tan diestramente ha desarrollado José Luis Mingote (1993: 135-153)—, podría estar mostrando una práctica protectora de los sembrados ampliamente documentada en la Península y otros lugares europeos y del norte de África.

Estas pequeñas variaciones en el contenido e interpretación de los cinco milagros recogidos por escrito en el siglo XIII, se ven completadas con la adición de otros muchos a través de los cuales se nos presenta la nueva personalidad del santo madrileño. El principal, cuando clavando su aguijada hace brotar agua de una peña para calmar la sed de su amo, ya ha sido ampliamente comentado más arriba, pero ahora también interesa resaltar las múltiples variantes de este episodio. Madrid, ciudad asentada 
sobre un inmenso acuífero se surtió hasta el siglo XIX de las aguas subterráneas. Para su aprovechamiento y distribución se empleaba un sistema introducido en la Península por los árabes consistente en localizar un vejigón de agua "pinchando" la tierra en un lugar algo elevado respecto a la ciudad y a través de conducciones subterráneas, encauzar y distribuir el preciado líquido hacia las diversas fuentes. Son los llamados aviajes de agua" que se completaban con los numerosos pozos y norias existentes dentro del núcleo urbano. Aunque está claro el temprano origen de esta técnica, en Madrid no se desarrolló plenamente hasta que el crecimiento de la villa fue demandando la multiplicación de los viajes. Esto sucedió sobre todo a partir del asentamiento de la Corte, que conllevó un rápido y constante aumento de la población por lo que, a principios del xvI, se buscaban poceros para crean nuevos viajes.

Lo que San Isidro hizo para localizar y hacer brotar el manantial de su nombre recuerda bastante la conducta de los zahoríes, que auxiliados con una varita se valen de ella para averiguar en qué lugar se encuentran las aguas subterráneas. Madrid necesitaba ampliar sus puntos de abastecimiento y San Isidro, siempre al servicio de los madrileños, se convierte en pocero especializándose en este tipo de milagros hidráulicos. Así serán varios los pozos que hace brotar en la villa, tales como el de la calle Toledo, situado en una casa perteneciente a los herederos de Francisco Vera, casualmente regidor de Madrid, y cuyo linaje reivindica ahora descender de otro de los amos del santo. Como el manantial que hiciera para Iván Vargas, este pozo también tiene propiedades curativas, no sólo para los hombres, sino especialmente para eliminar las sanguijuelas de las bestias. Aunque han pasado nada menos que cuatro siglos desde que muriera, Villegas no tuvo ningún reparo en avalarse en la tradición oral para este (Martínez Arancón 1978: 412) y otros relatos no incluidos en el Códice. Un pozo más hizo en Madrid en la calle Mayor a petición de doña Nufla, que habitaba en las casas del médico Jaime Vera (y vuelve a aparecernos este linaje reivindicando su vinculación con el patrón madrileño). La mujer se queja al santo de que las fuentes quedaban muy alejadas de su casa y éste hace brotar el agua de una peña. Nuevamente la tradición oral, pasando de unos a otros dueños la noticia, es el único aval para este prodigio. Además se incluyen referencias a otros dos pozos en la calle de Toledo reiterándose que las aguas surgidas no sólo son potables sino milagrosas, siendo una de las cualidades más alabadas su capacidad de sanar las fiebres tercianas, cuartanas y calenturas, por lo que se llevan para los enfermos. Tal es su fama que los poceros madrileños cuando emprenden su trabajo invocan al santo consiguiendo así culminar con éxito la empresa. 
Un episodio de indudable sabor madrileño y gran resonancia iconográfica es el llamado milagro del pozo. En la versión renacentista, Isidro y su familia vivieron en Madrid en la casa que los Lujanes tenían junto a la Capilla del Obispo (los descendientes de los Vargas, sus primeros amos) y la iglesia de San Andrés. Un día, al regresar del trabajo, el santo encontró a su esposa toda afligida porque su pequeño hijo había caído en el pozo pues, por su puesto, allí existía uno del que abastecerse. El matrimonio se puso a orar junto al brocal y las aguas subieron hasta el borde con el niño sano y salvo flotando encima (Martínez Arancón 1978: 414).

Pero su nueva personalidad urbanita no va en detrimento del labrador primitivo, sino que, por el contrario, también su hagiografía se ve completada con otras narraciones en este ámbito. Así, Villegas amplía sus trabajos como labrador en los alrededores de Madrid con una estancia entre Caraquiz y Torrelaguna, lo que cuadra bastante bien con el origen asignado a su esposa que, según algunos autores, conoció allí. En la zona se vuelven a repetir variantes de milagros anteriores, además de multiplicarse los amos. La más común es hacer brotar manantiales para calmar la sed de éstos - siguiendo punto por punto el esquema de su primera intervención en Madrid- o también por otras causas y así surgen nuevas linfas en Val de Salud (Valpermín) y en la Peña (tierra de Uceda, cerca de Caraquiz).

Las variantes de uno de sus milagros (la multiplicación de alimentos), repetidas veces y con diversos amos reiterado, nos muestra el cambio de carácter que ha sufrido el personaje: En el códice primitivo, Isidro destinó gran parte del trigo reservado para sus necesidades en alimentar a unas palomas hambrientas y, tras la molienda, la harina resultante se había multiplicado milagrosamente. Ahora el trigo que se va a moler, o más frecuentemente a aventar, pertenece al dueño de la tierra: Isidro pide a éste que le deje repetir la operación con la paja restante y si quedase algún grano más, pueda dárselo a los pobres. El amo accede pero, tras la multiplicación milagrosa, piensa que su siervo le ha engañado, por lo cual éste opta por darle al propietario el producto resultante de su milagro y pedir permiso para repetir otra vez el prodigio y así poder alimentar a los menesterosos. Es decir, por encima de los indigentes o de los pájaros, el primer beneficiario de su milagros es siempre el amo de turno que ve surgir manantiales en sus campos y multiplicarse el producto de sus cosechas, gracias al más leal e influyente ante Dios de todos sus siervos.

El santo, que abandonaba su trabajo para dedicarse a la oración enfrentándose a su señor y siempre anteponiendo lo espiritual a lo material, se ve ahora pluriempleado: en Madrid como pocero y agricultor y en el campo pasando de tierra en tierra y de amo en amo repitiendo sus 
intervenciones milagrosas. Pero la transformación más mundana del personaje vendrá provocada por su propia esposa, no la anónima mujer medieval sino la renacentista María de la Cabeza, quien le ocasionó tantos quebraderos a su esposo que bien podría ser esta la causa de su sobrenombre.

Según el códice medieval, el patrón de Madrid estaba casado, contaba al menos con un hijo, y al morir estuvo acompañado por su esposa. Pero este matrimonio que encajaba con bastante facilidad dentro del modelo de santidad islámico, ocasionaba bastantes problemas en el cristiano. Desde finales del siglo XII y durante el XIII, tímidamente se incorporaron los laicos al santoral; el matrimonio deja de constituir un obstáculo insalvable, pero lo cierto es que la vida conyugal se considera que no aporta nada al ideal de perfección cristiana y los casados normalmente terminan por abandonar a su familia para ingresar en un monasterio, desarrollan gran parte de su sagrada vida tras enviudar, o, al menos, en algún momento realizan votos de castidad perpetua (Vauchez 1991: 28). También a partir de la Baja Edad Media las mujeres, no sólo las reinas, se han comenzado a incorporar al santoral. Para conjugar los datos del códice medieval con los requisitos de santidad vigentes, Alonso de Villegas incluyó la siguiente narración: Tras el milagro del pozo por el cual el santo matrimonio recupera al hijo que había caído dentro, en agradecimiento a Dios deciden hacer votos de castidad. Para evitar tentaciones, María se marcha a Caraquiz, desde donde todos los días se desplaza a una ermita para encender la lámpara y encargarse de su mantenimiento, gracias a las limosnas recibidas, mientras, Isidro permanecía en Madrid.

Pero como no hay cosa por buena que sea, que no la pueda interpretar mal la malicia humana, acusáronla unos calumniadores a S. Isidro, diciendo: que su mujer con capa de devoción vivía deshonestamente, conversando con los pastores que estaban a la orilla del Jarama [...] (Villegas 1978: 415).

Ante la mancilla de su honor no le quedó más remedio al santo madrileño que viajar de improviso a Caraquiz para espiar a su esposa y comprobar qué había de verdad en todo aquello; viendo personalmente cómo ella, al llegar a las orillas de Jarama, tendía su mantilla sobre las aguas colocándose encima y cruzando por este procedimiento el río. Tal vez hoy en día nos cueste comprender qué valor tiene este milagro como prueba del comportamiento honesto, pero a finales del siglo XVI, al parecer resultaba irrefutable e Isidro regresó satisfecho a Madrid.

Si al patrón madrileño, como a la mayoría de los santos, se les puede reprochar que cuando se hacen famosos por un tipo de prodigio, se dedican a repetirlo con ligeras variantes de localización o tiempo, con su 
esposa, en manos de Villegas y aún más en hagiografías posteriores, como la de Nicolás Joseph de la Cruz, este tema raya en el ridículo, y una y otra vez Isidro es inquietado por las murmuraciones que le obligan a retornar a Caraquiz para vigilar el comportamiento de su mujer. Mientras, ella no cesa de tender su mantilla y cruzar el Jarama, como prueba de su comportamiento honesto, sola, con testigos, en compañía de su esposo, etc. Hasta el punto de que es este milagro, cuyo único fin es limpiar su honor, el que la ha caracterizado y prácticamente en todas sus representaciones iconográficas, Santa María de la Cabeza aparece cruzando el río sobre su mantilla con una lámpara de aceite en la mano y un tizón en la otra.

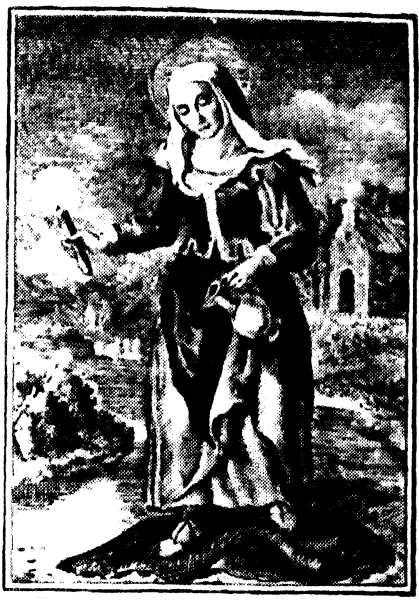

FIguRA 10.-Santa María de la Cabeza. Museo Municipal de Madrid.

Como es sabido, en la literatura del Siglo de Oro el "honor" será uno de los grandes temas, por lo que resultará fácil comprender el enorme partido que Lope de Vega obtuvo de este relato.

Antes de adentrarnos en este autor, tan sólo queremos resaltar que en la narración de la muerte del santo y sus milagros póstumos, Alonso de Villegas sigue, casi literalmente, el contenido del códice medieval, con la única licencia de añadir la intervención en apoyo del bando cristiano en la Batalla de las Navas de Tolosa que, finalmente, a pesar de las dudas y controversias que suscitara, quedó incluido en el proceso de canonización.

\section{El San Isidro de Lope de Vega y la divulgación popular}

En la vida y la obra de Lope San Isidro tiene una importancia fundamental, y su poesía contribuyó de forma esencial a la difusión de su culto y popularización, le amaba por razones de paisanaje y por su espíritu llano y democrático. Además la vida de San Isidro se presta a la realización de aquellos cuadros idílicos, en que tanto se complacía la musa de Lope, ataviándolos, no con los falsos colores de la égloga, sino con los genuinos de la vida rústica de Castilla en los primeros tiempos de la Reconquista, tal como su alma de poeta épico la reconstituía o adivinaba (Menéndez Pelayo p. CI en Lope de Vega 1964).

Como ya comentamos, fray Domingo de Mendoza había encargado una biografía en verso del patrón madrileño a Lope de Vega, aunque se de- 
moró bastante en enviarle los "papeles verdaderos y fidedignos" (Lope de Vega 1599: 272), que asegura son originales, tal y como le había demandado el autor, lo que no hizo hasta 1596, cuatro años después de la publicación de la versión de Alonso de Villegas, saliendo a la luz Isidro. Poema Castellano en 1599. La obra, tal vez demasiado amplia, con párrafos y cantos enteros de gran farragosidad y múltiples disertaciones eruditas, contiene sin embargo fragmentos de enorme belleza y es, sin ningún lugar a dudas, el germen de las tres comedias posteriores dedicadas al santo, además de la fuente principal de las divulgaciones populares en pliegos de cordel y aleluyas. Frente a las comedias presentaba la ventaja de incluir descripciones y narraciones (no sólo los diálogos teatrales) que podían ser extractados y copiados posteriormente. Así por ejemplo, la caracterización del santo que Lope realizó aquí, literalmente o con ligeras variantes, ha prevalecido incluyéndose en gran parte de la literatura posterior. Con gran acierto, García de Villada (1922: 115) vio en el poema aspectos del romancero, de las comedias de santos, de los autos sacramentales y de la comedia profana. Además, el poema se prestaba a una nueva versión reducida extractando los párrafos o fragmentos más interesantes, lo que efectivamente se hizo, conociéndose como los Jardinillos de San Isidro.

En primer lugar quisiéramos destacar que Lope de Vega se ajustó al códice original con mucha más fidelidad que Alonso de Villegas y aunque debía de conocer su obra, no se ven influencias de ella, mientras por el contrario, sí podemos encontrar frases literales del códice que en sus manos aparecen en verso sin forzar para nada su estructura. La preocupación por esta fidelidad es una constante y ya en los "Preliminares" el Fénix declaraba:

Todo lo que scriuo es autentico: y cosas ay, que los que nacimos en esta villa, las sabemos en naciendo, sin que nadie nos las enseñe, y diga, que no es pequeño argumento de la santidad deste varon excelente: y por mi mesmo saco yo esta verdad, pues supe que la fuente de su ermita la hizo con su aguijada, y que araua en aquellos campos con los Angeles, sin otro maestro, que auver nacido en ellos (Lope de Vega 1599: 275).

Como vemos, el autor se preocupa de aclarar de dónde proceden las innovaciones que ha añadido al manuscrito primitivo. El largo poema está dividido en diez cantos con el siguiente contenido: El primero se dedica a narrar cómo Isidro nace y se cría virtuosamente y, llegada la edad oportuna, los campesinos hablan de casarle. El segundo está dedicado a la boda con una descripción del ajuar, la dote, etc., finalizando con la acusación realizada por los compañeros campesinos ante su amo Iván 
Vargas de que no atiende debidamente su trabajo por dedicar el tiempo a la oración (y aquí sí aparece este linaje —del que con acierto Lope aclara que era uno de los más antiguos de Madrid- ya completamente consolidado como el del amo primitivo del santo). El canto tercero en el que Iván espía a Isidro viendo a los ángeles arando con él, suaviza un poco el tono de enfrentamiento de la narración original, además de añadir a los ángeles, que, como ya había aclarado en los "Preliminares", es algo que todos los madrileños saben sin necesidad de más fuentes o aclaraciones que las proporcionadas por el sentido común. El cuarto canto está dedicado en una parte al nacimiento de su hijo (totalmente recreada o inventada) y seguidamente narra con total fidelidad dos de los milagros del Códice: el del lobo que atacaba al jumento del santo

I S I D R O.

POEMA CASTELIANO De Lope de Vega Carpio, Secretario del Marques de Sarria.

IN RVESEESCRIVELA VIDA Ifu Perron Livino.
fis

DIRIGIDA A LA M V Y infigne villa de Madrid.

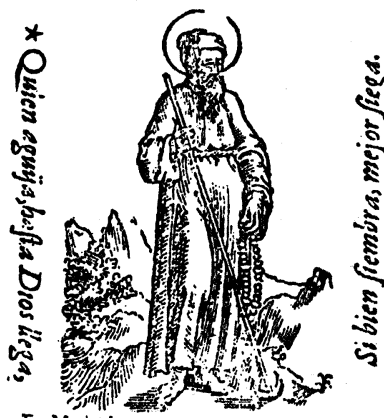

En Mudrid, Pur Lais Sancbez. Año 1999.

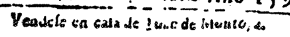

FIGURA 11.-Portada de Isidro. Poema Castellano de Lope de Vega. mientras oraba y el de la olla vacía que aparece llena para dar de comer a un pobre en su casa. En la multiplicación de la harina, tras alimentar a unas palomas hambrientas con el grano que llevaba a moler, aparece la variante -que luego prevalecerá- de que el contenido de los sacos pertenecía a Iván Vargas, frente a la versión original donde se especificaba que era "para sus necesidades". Esto es contado en el canto V, donde también se narra el último de los prodigios del Códice: la multiplicación del contenido de una olla, tras el banquete de una cofradía, para dar caridades a los pobres, donde se añade el nombre de esta asociación: Cofradía de Nuestra Señora. Hasta aquí Lope se ciñe con bastante precisión al Códice, pero será en los últimos cinco cantos donde encontremos las variaciones más interesantes, además de las prolijas disertaciones. Así el canto sexto está dedicado a la comida de estos indigentes, en la cual cada uno de ellos va contando su historia. En el octavo, Isidro habla con un ermitaño que le cuenta los orígenes de la Virgen de Atocha. El noveno está dedicado a los milagros póstumos recogidos por Juan Diácono, al que sigue, como es la norma, con bastante fidelidad, mientras que en el décimo y último se narra el milagro de la reina Juana, la mujer de Enrique II, cuando le arrancó un brazo y sufrió un repentino y grave malestar hasta su devolución. Frente a Alonso de Villegas nada dice de otras muchas invenciones que éste había incluido en su hagiografía, como las 
estancias y amos que tuvo en el norte de Madrid y sus milagros relacionados con el agua, tales como la creación de nuevos pozos o la reiteración de los mismos en contextos o con amos diferentes.

Deliberadamente hemos dejado para último lugar el contenido del canto VII, el único en el que nos vamos a detener, dedicado completamente a lo que podríamos denominar "los celos o el honor de San Isidro", es decir el espinoso tema de María de la Cabeza y su comportamiento tras los votos de castidad que, en esta versión, no se producen, después del milagro del pozo, sino por una iniciativa del labrador. Más que el comentario de este texto, merece la pena reproducir algunos fragmentos literales, con los que se comprenderá sin problemas, la actualización y dramatización, dentro de los más puros esquemas de la literatura del Siglo de Oro, de tan jugoso episodio. En primer lugar hay que destacar que de lo que se acusa a la esposa no es de entretenerse a hablar con los pastores, como decía Villegas, sino de que ella tiene amores con un pastor concreto. La personalización de la Mentira se acerca a Isidro y comienza a decirle verdades como puños:

Pues la mentira induzida De Iezabel, y el demonio, Para el falso testimonio, a Isidro llego vestida Del honor del matrimonio. $\mathrm{Y}$ tomando aquella forma, que para engañar conforma, Canas, rosario apariencia, Buen celo, honrada presencia, Desta manera le informa.

Isidro, tu buena vida, Tu caridad y oración, Al cielo agradables son: Pero es justo que las mida El compas de la razon. Porque los excessos tales, Aun siendo espirituales, Ella es bien que los modere, $\mathrm{Ni}$ tampoco el cielo quiere Mezclados bienes y males.

Al que es, Isidro casado, Menos religion se pide: Si en una carne reside El ser de dos, viue errado, El que esta unidad diuide.
Tu muger por tu rigor

$\mathrm{Ha}$ hecho un notable error, Por viuir en soledad: Lot fue justo en la ciudad, $\mathrm{Y}$ en el monte pecador. [...] Con virtud que nadie iguala, Estas de descuiddos lleno, Mas querer tu por se bueno, Que sea tu muger mala, Es lo que, Isidro condeno. Pero ya es tiempo que vença La razon a la verguença, No lo quiero dilatar, Pues no es discrecion dexar Lo que ha dezir se comienza

$Y$ no digas que el honor Del mundo a ti no te toca, Que es una respuesta loca, $Y$ haze la ofensa mayor, Quien tu descuido prouoca. Que tu injuria a Dios se extiende Pues el pecado le ofende, [...]

Mira a Salomon si piensa, 
La vengança de la ofensa, con los zelos, y el furor.

Donde ni ruegos, ni amor, son del castigo defensa.

Mas yo pienso que no eres Tan rudo, aunque Labrador, Que no entiendas que es honor, No porque el del mundo quieres, Que es el del cielo mejor.

Mas porque estando tu vida

En tanta altura subida,

Caeras mucho de honor falto,

Porque lo que esta mas alto,

Suena mas en la cayda.

Pues mira que ha de dezir La fama, que es por tu culpa, Porque a la muger disculpa El deshonesto viuir,

$\mathrm{Y}$ al hobre [sic] aunque ausente culpa. Porque el mundo ha recibido,

Por la infamia en que ha caydo Quien tiene tan baxa prenda, Que puesto que no lo entienda, Viua sin honra el marido.

Harto bien estas aqui, En tu tierras y labores, y Maria en sus amores, Como apartada de ti, Comun entre los pastores. Bueluela a tu compañia, $Y$ deste error la desuia, O para siempre la aparta, Que de otra manera Marta Boliuo por otra Maria.

Pero matarla es razon, Pues tiene culpa, y tu impero, No sufras tal vituperio, Que hasta el Cisne, y el Leon, Saben vengar su adulterio. Buscala, riñela, y dala Pena que a la ofensa iguala Quien haze justicia, es justo, no digan que por tu gusto: Ha venido a ser tan mala.
Passa en el campo los dias, Tan a su gusto y plazer, Que para darlo a entender, Parece que Ieremias, Hablaua con tu muger. A Ierusalen dezia, Que sus adulteros via En el campo, y los collados Mira que viuos traslados De la adultera María.

Isidro, quando llego La mentira en este punto, quedo de color difunto, que le parece que vio El cielo a la tierra junto. Porque dezir que en Maria Vicio deshonesto auia, Tan impossible juzgaua: $Y$ en esto no se engañaua, que santamente viuia.

\section{[...]}

$\mathrm{Y}$ que a los ojos que son Puertas de penas y gozos, Quita el alma los rebozos, Tragando a cada ringlon La muerte buelta en sollozos, Assi de Isidro turbados Los sentidos alterados, Solo pudo responder, Yo tengo buena muger, Los malos son mis pecados.

Diuidieronse los dos, Como no le contradixo, A su discurso prolixo: Quedose Isidro, y a Dios Estas palabras le dixo. Andaua con la inocencia De mi segura conciencia En la mitad de mi casa, Ignorando lo que passa, Por mi poca diligencia.

Crey, Señor, de Maria El vergonçoso exterior, La caridad y el amor: 
Que el alma con que lo hazia, Vos la conoceis, Señor.

Crey, y aun pienso que creo, Que no pudo auer desseo, $\mathrm{Ni}$ palabra descompuesta, En la boca mas honesta, Que he visto despues que veo.

Crey de su penitencia, Vigilia, oracion y ayuno, que no fuera vicio alguno, Poderoso en su inocencia, Por mas que fuesse importuno. [...]

Es diuina su humildad, La fe en ella resplandece, Toda alabança merece, Pero sin la castidad, De toda virtud carece. [...]

Para esto di, Maria, De tu Isidro te apartauas? Por perderte me engañauas? Con tan falsa hipocresia Mi casa y braços dexauas? Embuelta en pobre vestido, Rostro humilde y abatido, Tu lasciuia virtud fue: Ay de mi, no me guarde, Como era tu bien fingido.

Triste yo que deuo hazer? Mas es possible que pudo, quien tuuo tan fuerte escudo, Como es la humildad, caer? Temo, creo espero, y dudo. Señor, grande prueua ha sido: Paciencia, Señor, os pido, Si a los que amais castigais, Porque tanto mas me honrais, quanto soy mas perseguido.

Con esta que hazer intenta, Del que es enemigo amigo, A tener quedas me obligo La lengua para la afrenta,
La mano para el castigo. $\mathrm{Si}$ vos mandais, quiero $\mathrm{yr}$, Porque assi pueda reñir Lo passado estando ausente, $\mathrm{Y}$ remediar lo presente, $\mathrm{Y}$ estoruar lo por venir.

Con aquesta confusion, Puesto que dudoso estaua, A Xarama endereçaua Sus passos y su passion, que a cada passo aumentaua. Quantos topaua reñian Por zelos, todos dezian, que auian de herir y matar, Porque era infamia callar, Los que sin honra viuian.

Alli via una muger, $\mathrm{Y}$ un hombre metiendo mano Por otro caso liuiano: $\mathrm{Y}$ todo deuia de ser Sueño fantastico y vano. Mas lexos otro dezia, Mala muger, este dia Tu sangre laue mi honor: que a cada passo el temor Ilusiones le ofrecia.

Al passar por las aldeas, Via con tiernos chillidos Los paxaros en los nidos, Como con palabras feas Las mugeres y maridos.

En los campos de Xarama Ohia la fiera brama, De los venados zelosos, Y mugidos espumosos De los nouillos de fama.

En las sierras, antes mudas, A los zelosos ganados, Ohia atronar los prados De las testas forcejudas, Los golpes executados. Todo daua testimonio Del honor del matrimonio. [...] (Lope de Vega 1599: 352-354) 
Sin lugar a dudas, el tema y la forma del canto VII, no sólo totalmente profano, sino además centrado en el "honor", debieron hacer las delicias del público de finales del XVI, contribuyendo, de forma decisiva a la divulgación hagiográfica del patrono madrileño que se presenta como un campesino más renacentista que medieval, es decir, cercano a los intereses y gustos no sólo de las clases populares, sino también de las urbanas que en esta época empiezan a volver sus ojos al campo como un modelo de vida idílico.

Diez y ocho años después, un Lope de Vega, mucho más maduro literariamente y centrado ya en la composición de comedias que triunfan en las corralas madrileñas, ávidas de este tipo de espectáculos, dedica a Isidro una de ellas. Aunque todavía faltan dos años para su beatificación y cinco para la canonización, no duda en titularla: San Isidro Labrador de Madrid (Lope de Vega 1964: 394-443). En la deliciosa obra, considerada como una de las mejores del autor, se encuentran muchos de los temas desarrollados en Isidro. Poema Castellano, pero han desaparecido las farragosas disertaciones y las notas eruditas. Con indudable frescura y alegría, se plasma un ambiente campesino del que se dan todo tipo de detalles, reflejándose las costumbres de la época. Especialmente ensalzados han sido los versos dedicados a la boda, las escenas de guerreros (con las que arranca la comedia al regresar Iván Vargas del campo de batalla) y las campestres. Isidro ha evolucionado, ajustándose más y más a las demandas de la época y al deseo de extender y popularizar su culto.

Así por ejemplo, el comportamiento antisocial de Isidro, que provocó la incomprensión o enfrentamiento entre el santo y el resto de los campesinos, tan marcados en el códice medieval y todavía patentes en el Poema Castellano, ahora se suavizan totalmente. De esta manera no son ellos quienes le acusan ante Iván Vargas de descuidar sus obligaciones laborales, sino el demonio disfrazado de labrador. Igualmente, el compañero que le tachó de loco cuando al ir al molino Isidro echó parte del grano para alimentar unas palomas, en la obra de Lope se convierte en una personificación de la envidia (Lope de Vega 1965: 421). Asimismo cuando Isidro estaba orando en la ermita de la Magdalena y su jumento es atacado por un lobo, ahora esto sucede por obra del demonio y los muchachos que le avisan instándole a abandonar sus rezos, lo hacen también por incitación del diablo.

Ante la imposibilidad, por las limitaciones de espacio, de incluir un análisis pormenorizado de la obra y toda la información sobre la vida popular en ella contenida, tan sólo vamos a reproducir a modo de ejemplo la enumeración de la dote que el padre de María le va a dar con motivo de su boda: 
JUAN (padre de María) Yo te doy primeramente mil maravedís en plata $y$ en oro.

ANA

Mirad si trata su hacienda liberalmente.

JUAN

Entre ellos hay un escudo que treinta años he guardado, tan bueno, limpio y dorado, como cuando hacerse pudo; porque desde que cayó en mis manos, le guardé para esta ocasión; no sé si le gastarás o no; pero si aquella sin ley a gastalle te obligare, haz por tu vida, que pare en comprar un gentil buey.

Sin esto, te pienso dar dos colchones y un jergón; $y$ advierte que nuevos son, que no te quiero engañar; no ha diez años que se hicieron, ni seis veces se han lavado; seis sábanas de delgado lienzo, que en dote me dieron.

Cuatro almohadas y un banco; una silla de costillas, trébedes, sartén, parrillas, y un paño de manos blanco; no ha mucho que estaba entero y en toda su perfección mal le dé Dios al ratón

que le hizo un agujero.

Dos sargas de linda mano;

la una tiene a David

y el gigante que en la lid

tendió sobre el verde llano;

ella está a medio traer,

porque era el lienzo algo flojo;

fáltale al gigante un ojo,

pero no se deja ver.

La otra tiene pintado

el prodigio, que dirás que viendo en la artesa estás los lechones y el salvado; están con ojos extraños mirando el prodigio esquivo, y $\tan$ gordos que a estar vivos, tuvieras para dos años.

Sin otras cosas así que por menudencias dejo, te daré peine y espejo; y por no cansarte aquí no te digo los vestidos y camisas de tu esposa; tus camisones es cosa que revientan de polidos.

Ella lleva allá también su arca grande, donde puso aspa, lino rueca y huso, que sabe gastar muy bien. Para después de mis días una viña, un pegujar, y algo más hay que te dar, son tres cabras con sus crías.

(Lope de Vega 1965: 401-402)

El tema del honor o los celos de San Isidro ocupa buena parte del segundo y el tercer acto, aunque se ha suavizado bastante el tono dramático de la obra anteriormente citada. Merece la pena comparar los párrafos en los que Isidro, tras ser avisado de supuesto adulterio de su mujer, se va paseando por la orilla del Jarama. Si en el Poema Castellano, como acabamos de ver, él sólo se encuentra con obscenidades y adul- 
terios, ya sean protagonizados por hombres o animales, ahora todo el episodio se cierra con unos bellísimos versos que ensalzan la vida y costumbres campestres.

MENTIRA.

Porque si a ser santa fue, tales sus costumbres fueron, que no fue Tais ramera más loca, pues no hay pastor con quien no trate de amor en toda aquella ribera.

ISIDRO

¡Válgame Dios!

ENVIDIA

Bien haréis

en que la saquen de allí

ISIDRO

¡Que mi mujer vive así! [...]

¡Piadoso llanto me ciega! ¡Ay, María; tú, de quien yo aprendía honestidad! ¡Ay, cómo la soledad no les viene a todos bien! ¡Tú, cuyas santas costumbres, en la noche de mi error, daban mayor resplandor que al cielo sus altas lumbres! ¡Tú, María, honesta y buena, de cuya boca no oí palabra que, para mí, no fuese limpia azucena! ¡Tú deshonesta! ¡Tú ya tan pública pecadora! ¡Tú! ¡Llorad, ojos agora! ¡Vuestra luz perdida está! ¿La mitad del alma mía deshonesta? ¿Ojos, llorad, que perdida la mitad, peligro correr podría! (Lope de Vega 1965: 433-434)
MENTIRA

¿De qué es aqueste rumor?

ENVIDIA

Pastores deben de ser,

que como el agosto han hecho,

a la ermita de María

traen una cruz.

[...]

MÚSICOS

Vuela caballito, vuela ${ }^{\text {; }}$

darte he yo cebada nueva.

MÚSICO 1

Hicieron su agosto

MÚSICO 2

por aquestas vegas,

MÚSICO 1

donde se juntan,

MÚSICO 2

$\mathrm{Y}$ casados quedan,

MÚSICO 1

Manzanares verde

MÚSICO 2

y Jarama bella.

MÚSICO 1

Los pastores suyos,

\section{MÚSICO 2}

después de la siega,

MÚSICO 1

y de espigas rojas

${ }^{9}$ En el original pone vuelo, evidente error que rompe la rima y se contradice con las otras dos ocasiones en que se repite este estribillo. 
MÚSICO 2

una cruz compuesta,

MÚSICO 1

vienen a la ermita,

MÚSICO 2

quieren ofrecella.

Vuela, caballito vuela;

darte [he] yo cebada nueva.

MÚSICO 1

A Santa María,

MÚSICO 2

rosa madreselva;

MÚSICO 1

a su Hijo hermoso,

MÚSICO 2

lirios y azucenas;

MÚSICO 1

a San Juan Bautista,

MÚSICO 2

olorosas hierbas;
MÚSICO 1

a San Pedro Apóstol,

MÚSICO 2

mastranzo y verbena;

MÚSICO 1

a San Roque hermoso,

MÚSICO 2

trigo de las eras;

MÚSICO 1

a San Sebastián,

MÚSICO 2

trébol y mosquetas;

MÚSICO 1

al gran San Cristobal,

MÚSICO 2

pinos de la sierra.

Vuela caballito, vuela;

darte he yo cebada nueva.

(Lope de Vega 1965: 437-438)

Aunque técnicamente mejor compuestas, son de menor interés las otras dos comedias que dedicó al Santo: La niñez y La juventud de San Isidro (Lope de Vega 1965: 326-360 y 362-392), representadas en 1622 durante las fiestas de canonización bajo el balcón del Palacio, desde donde fueron presenciadas por los reyes. La primera, totalmente inventada, recrea la niñez del patrón madrileño sin ninguna alusión al Madrid islámico; se trata del hijo analfabeto de un campesino que ya en la infancia recibe una visita de Jesús proponiéndole su amistad. La segunda, se inicia con las bodas de Isidro y María y narra algunos de los milagros del Códice como el de los ángeles arando (quien le acusa ante el amo será el diablo, mientras un campesino le defiende). También se trata del milagro de las palomas y -icómo no! - alcanza un amplio desarrollo el tema estrella: los votos de castidad, las murmuraciones y el milagro de María (el paso del Jarama sobre su mantillo) para probar su castidad, aunque manteniendo un tono mucho más prudente que en las versiones anteriores. 


\section{LA DIFUSIÓN POPULAR DEL CULTO A SAN ISIDRO}

En su interesante artículo "Hagiografía popular y comedias de santos", María Cruz García de Enterría (Blasco, Caldera y Álvarez 1992: 71-82) analiza las influencias recíprocas entre la hagiografía popular, los pliegos de cordel y las comedias de santos. Según esta autora, en los primeros años del siglo XVII se produce un aumento significativo de las poesías en verso (pliegos de cordel), las aleluyas y del teatro hagiográfico, en parte provocado por los efectos de la Contrarreforma, encontrándose en estos cauces de difusión, un método cómodo para llegar al pueblo y difundir desde los escenarios o la calle, las vidas de santos.

Sin duda, como afirma la autora, la hagiografía fue fuente directa de muchas de las comedias de Lope, aunque en el caso de San Isidro, como hemos visto, el poeta se inspiró directamente en el manuscrito original del siglo XIII, manteniendo su obra una fidelidad mayor que la del propio Alonso de Villegas, al que probablemente también había leído, tomando de él los episodios sobre el honor de María de la Cabeza. Asimismo García de Enterría afirma que los pliegos de cordel pudieron ser otra de las fuentes de inspiración del Fénix, aduciendo como ejemplo, uno encontrado en el Brithish Museum, "Recopilación de los milagros y maravillas de san Isidro de Madrid" publicado en 1606 (es decir once años antes de la comedia de Lope de Vega San Isidro Labrador de Madrid) (García de Enterría 1977: 56). Sin embargo, en este caso concreto, discrepamos, ya que, como vamos a mostrar, los pliegos dedicados al patrón madrileño tienen como principales fuentes de información, por una parte, la hagiografía de Alonso de Villegas, pero sobre todo el Isidro. Poema Castellano de Lope de Vega, publicado en 1599 (anterior a todas las versiones populares que conocemos sobre la vida del santo) y que, por ser una composición narrativa en verso, se prestaba con gran facilidad al recorte o extracto de algunos de sus fragmentos para difundirlos en los pliegos de cordel. De esta manera el romance citado no sería antecedente de la comedia, sino consecuente del poema. Asimismo, en otros pliegos encontramos versos y párrafos claramente inspirados o copiados de las tres piezas teatrales que le dedicó a Isidro o incluidos en los versos de la Justa Poética organizada con motivo de las fiestas de beatificación, en la que concursó utilizando por primera vez el seudónimo de Maestro de Burguillos.

A modo de ejemplo, vamos a comparar algunos fragmentos de un pliego perteneciente a la colección: Pliegos del CSIC: Fondo de la Imprenta 


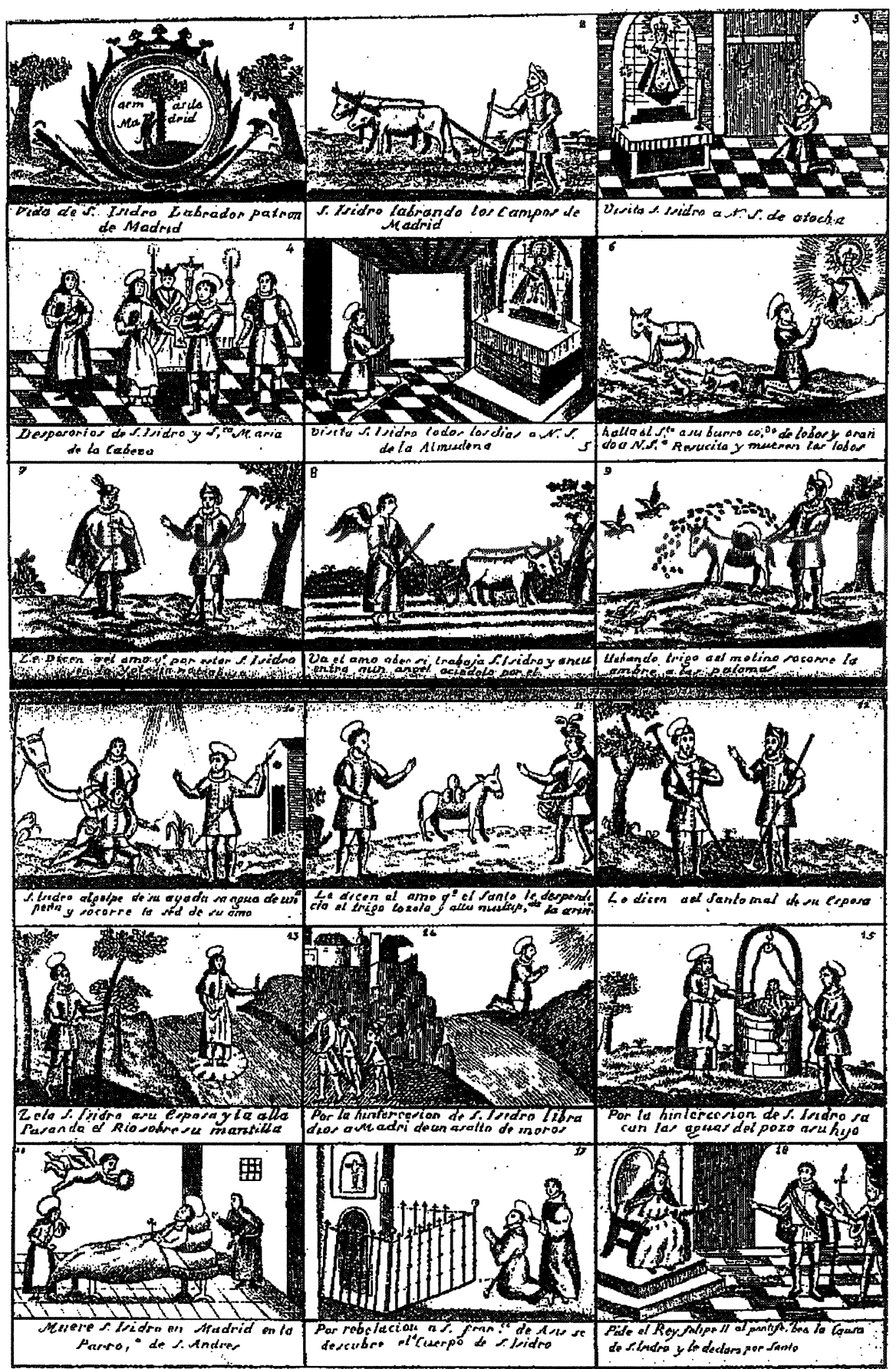

Figura 12.-Aleluya narrando la vida de San Isidro. Museo Municipal de Madrid. 
Hernando ${ }^{10}$ cuya impresión debe datarse a finales del siglo XIX o principios del $\mathrm{xx}$, pero que por los datos vertidos en él se debería retrotraer su primera edición a 1640. Comparemos en primer lugar las caracterizaciones de Isidro y María contenidas en el pliego y el Isidro. Poema Castellano:

Era Isidro alto, y dispuesto, Bien hecho humilde y modesto, Nariz mediana, ojos claros, En ver y en vergüenza raros, De andar suspenso, y compuesto. El cabello Nazareno, Bien puesta la Barba, y boca, $\mathrm{Ni}$ en grande excesso, ni poca. [...]

Era María trigueña, De ojos garzos, vergonçosos, Viendo y mirados hermosos, La boca honesta y pequeña, Los cabellos espaciosos.

(Lope de Vega 1599:394-395)
Era Isidro alto de cuerpo, de constitución bien hecha nariz mediana, ojos claros, y la barba muy bien puesta, el cabello hasta los hombros y humilde la vestimenta

Su esposa era Raçhel por la agradable presencia, y por su estremada virtud del siglo XII Rebeca; una estatura mediana bonita cara trigueña, buen cabello, pardo claro clavel la boca y pequeña, y según se ve en retratos, una nariz muy bien hecha.

(Anónimo: sig, 36/1127)

Asimismo, el autor anónimo del pliego sin duda conocía la Relación de las fiestas que la insigne villa de Madrid hizo en la canonización de su bienaventurado bijo y Patrón San Isidro, en la que se incluyó la "Justa poética al bienaventurado San Isidro en las fiestas de su beatificación" (Lope de Vega 1950: 158, 240-245, 269-270 y 286-294.) y las dos comedias: $L a$ niñez y La juventud de San Isidro (Lope de Vega 1965: 326-360 y 362392) y son varios los datos o fragmentos literales copiados de algunas de estas obras como la mención "Crióse en casa de Ibán/ de Vargas, cuya nobleza/ es de aquellas mas antiguas/ que se encuentran en la Iberia", que tiene su origen en el Poema, mientras que los versos, literalmente reproducidos al inicio de "Los ángeles labradores", tercera y última parte del pliego que comentamos:

${ }^{10} \mathrm{El}$ pliego nos ha sido facilitado por Antonio Cea quien lo analiza, junto con otros en su artículo «El pliego en verso de tema religioso como repertorio devocional público y privado" (Cea Gutiérrez en prensa). 


$$
\begin{aligned}
& \text { A ninguno, Isidro, el cielo } \\
& \text { Premió por arar tan bien, } \\
& \text { Porque fuiste sólo quien } \\
& \text { Aró con el cielo el suelo. }
\end{aligned}
$$

están literalmente tomados de la Justa Poética (García Villada 1922: 134).

San Isidro, el labrador medieval de influencias islámicas, al convertirse Madrid en la corte del Imperio español, ve como se recrea su imagen. Pero si la oligarquía y el clero madrileños hacen de él, gracias a la versión hagiográfica de Alonso de Villegas, el más fiel de sus siervos, al servicio de sus intereses, Lope de Vega lo rescata y lo devuelve al pueblo. Aunque se basa en los manuscritos originales, la reconversión del personaje se fundará, sobre todo, en el acercamiento a los gustos teatrales del momento con el tema del honor y en la recreación del mundo rural campesino de finales del XVI y principios del xvII.

\section{BIBLIOGRAFÍA CITADA}

Alvar Ezquerra, Alfredo (coord.), M. ${ }^{a}$ Elena García Guerra y M. $^{a}$ De los Ángeles VICIOSO RODRíGUEZ. 1993. Relaciones topográficas de Felipe II. Madrid. Vol. I transcripción de los manuscritos. Madrid: Comunidad de Madrid, Consejería de Cooperación/CSIC.

ARQuÉs, ENRIQue. 1953. Tierra de moros. Estampas de Folklore. Tetuán: Instituto General Franco de Estudios e Investigación hispano-árabe.

ANÓNIMO. s.a. "Vida del glorioso San Isidro Labrador, patrón de Madrid", "Alabanzas a San Isidro, sobre el milagro de la fuente" y "Los Angeles labradores". Colección de Pliegos de Cordel del CSIC: Fondo de la Imprenta Hernando, Madrid: Despacho Hernando. Arenal, 11, sig. 36/127.

ANóNimo. 1993. Los milagros de San Isidro (s. XIII) (facsímil del Códice). Transcripción de Fidel Fita revisada por Quintín Aldea. Traducción por Pilar Saquero SuárezSomonte y Tomás González Rolán. Madrid: Academia de Arte e Historia de San Dámaso, Arzobispado de Madrid.

AyUNTAMIENTO DE MADRID-ARChIVO DE LA Villa. 1932. Libros de Acuerdos del Concejo Madrileño. 1464-1600, edición, prólogo y notas por A. Millares Carlo y J. Artiles Rodríguez, archiveros-bibliotecarios. Vol. I. Madrid: Artes Gráficas Municipales.

Blasco, F. J., E. Caldera, J. Álvarez Barrientos y R. DE la Fuente, (eds.). 1992. La comedia de Magia y de Santos. Barcelona: Ediciones Júcar.

Birge VItZ, Evelyn. 1991. "From de oral to the written in Medieval and Renaissancce saints'lives", en Renate Blumenfeld-Kosinski and Timea Szell (eds.), Images of Sainthood in Medieval Europe: 97-114. Ithaca and London: Cornell University Press.

Caro Baroja, Julio. 1974. Las formas complejas de la vida religiosa. Religión, sociedad y carácter en la España de los siglos XVI y XVII. Madrid: Akal editor.

- 1992. Falsificaciones de la Historia (en relación con la de España). Barcelona: Ed. Seix Barral.

CÁTEDRA, MARÍA. 1997. Un santo para una ciudad. Barcelona: Editorial Ariel. 
CEA GutiérRez, Antonio. En prensa. “El pliego de cordel como repertorio devocional público y privado", en Luis Díaz de Viana (coord.), Palabras para el pueblo. La colección de pliegos del CSIC: Fondo de la Imprenta Hernando. Madrid: CSIC.

Christian, William A. 1991. Religiosidad local en la España de Felipe II. Madrid: Editorial Nerea.

CuARTERo y Huerta, Baltasar. 1967. "Orígenes de la Archicofradía Sacramental de San Isidro e introducción a sus corridas de toros en los siglos XVIII y $\mathrm{XIX}^{\text {". Anales del }}$ Instituto de Estudios Madrileños XXXX.

Delehaye, HIPpolyte. 1962. The legends of the saints. New York: Forham Universty Press.

FERNÁNDEZ MONTES, MATILDE. 1995. "El agua en las tradiciones madrileñas", en J. A. González Alcantud y A. Malpica (eds.), El agua: mitos, ritos y realidades. Actas del coloquio internacional celebrado en Granada, 23-26 noviembre, 1992: 121-15. Granada: Anthropos/Diputación de Granada.

- 1999. "Isidro el varón de Dios como modelo de sincretismo religioso en la Edad Median. Revista de Dialectología y Tradiciones Populares LIV, 1: 7-51.

Fernández Villa, Fray Domingo. 1987. San Isidro Labrador. Santa María de la Cabe$z a$, su esposa. León: Editorial Everest. S. A.

FITA, Fidel. 1886 a. "Madrid desde el año 1197 hasta el de 1202" y "Madrid desde el año 1203 hasta el de 1227. Boletín de la Real Academia de la Historia VIII, cuadernos II y IV: $141-153$ y $316-466$.

- 1886 b. "Año 1275. Leyenda de San Isidro por el Diácono Juan. Códice del siglo XIII, procedente del archivo parroquial de San Andrés“. Boletín de la Real Academia de la Historia IX: 97-157.

GaRCía DE ENTERRÍA, María CRUZ. 1977. Catálogo de los pliegos poéticos españoles del siglo XVII en el Brithish Museum de Londres. Pisa: Giardini Editori e Stampatori.

GaRCía VilladA, ZaCARÍAs. 1922. San Isidro labrador en la bistoria y en la literatura. Madrid.

Gentilli, LuCiana. 1989. Fiestas y diversiones en Madrid. La segunda mitad del siglo XVII. Relatos de viajeros europeos. Roma: Bulzoni Editore.

GÓmez IGLESias, Agustín. 1962. La Edad Media en Madrid. Madrid: Delegación Municipal de Turismo.

KleINBerg, Aviad M. 1984. Prophets in their own Country. Livin Saints and the Making of Sainthood in the Later Middle Ages. Chicago and London: The University of Chicago Press

JOSEPH DE LA CRUZ, NICOLÁs. 1790. Recuerdos de la Villa de Madrid. Vida de San Isidro Labrador Patrón de Madrid, adjunta la de su esposa Santa María de la Cabe$z a$, escrita por el R. P. Fr. Nicolás Joseph de la Cruz, del Orden de los Mínimos, Jubilado de derecho y número en la Provincia de las dos Castillas, y de Indias, Corrector que fue en el Convento de la Ciudad de Burgos, y últimamente en el de la Victoria de Madrid. Madrid: Imprenta Real (Ed. facsímil, 1986).

LOPE DE VeGA. 1599. Isidro. Poema Castellano de Lope de Vega Carpio, Secretario del Marques de Sarria, en que se escribe la vida del bienaventurado Isidro, Labrador de Madrid y su Patrón divino. Dirigida a la muy insigne villa de Madrid. Madrid: Luis Sánchez. (Ed. facsímil por Joaquín de Entrambasaguas, 1965, Obras completas de Lope de Vega. Tomo I Obras no dramáticas: 259-404. Madrid: CSIC).

- 1777. Relacion de las fiestas que la insigne villa de Madrid, hizo en la canonización de su Bienaventurado Hijo y Patron, San Isidro, con las dos comedias que se 
representaron y los versos que en la Justa Poetica se escribieron. Dirigida a la misma insigne villa por Lope de Vega Carpio. Madrid: Imprenta de Don Antonio Sancha. (Ed. facsímil, Madrid: Arco Libros, vol. XII).

- 1964. Comedias de santos Biblioteca de autores españoles desde la formación del lenguaje hasta nuestros dias (continuación) Obras de Lope de Vega IX. I Edición y estudio preliminar del Excmo. Sr. Marcelino Menéndez Pelayo de la Real Academia Española. Madrid: ediciones Atlas.

- 1950. "Justa poética al bienaventurado San Isidro en las fiestas de su beatificación" en Biblioteca de Autores Españoles: 143-158, 240-245, 269-270 y 286-294, ed. Rivadeneyra, Tomo 38. Madrid.

- 1918. Jardinillos de San Isidro. Selección del poema de Lope por Américo Castro. Madrid: Jiménez-Fraud editor.

MARTÍNEZ ARANCón, ANA. 1978. Santoral Extravagante. Una lectura del Flos Sanctorum de Alonso de Villegas. Madrid: Editora Nacional, Biblioteca de Visionarios, Heterodoxos y Marginados.

MATIlla TASCÓN, ANTONIO. 1983. "San Isidro en la Documentación Notarial", en San Isidro Labrador. Patrono de la Villa y Corte. IX Centenario de su nacimiento: 135151. Madrid: Academia de Arte e Historia de San Dámaso. Arzobispado de Madrid Alcalá.

- 1986. "Isidro de Madrid", en Aula de Cultura. Ciclo de conferencias sobre Madrid basta 1600. Madrid: Ayuntamiento de Madrid, Concejalía de Cultura e Instituto de Estudios Madrileños.

Millares Carlo, Agustín. 1971. Contribuciones documentales a la bistoria de Madrid. Madrid. Instituto de Estudios Madrileños/ CSIC.

Mingote CALDERÓN, JosÉ Luis. 1993. "Un milagro de San Isidro relacionado con los ritos de protección del grano durante la siembran: RDTP XIVIII: 135-153.

ORDENANZAS. 1790. CONSTITUCIONES Y MONTE PIO DE LA ARCHICOFRADIA DEL SS.MO SACRA.TO CONCEPCION DE NRA S.ra S.n YSIDRO Labrador, y Almas del Purgatorio, de las Yglesias Parroquiales, de S.n Pedro el Real y S.n ANDRES, de la Corte de Madrid, Canonicamente, eregida y, agregada con autoridad Apostolica a la de S.ta Maria de la Minerva de Roma Orden de Pred.s Nuevamente recopiladas y aprobab.s por el Real y Supremo Consejo de Castilla. en 18 de Junio de 1790. Madrid.

QuintanA, Gerónimo. 1629. A la muy antigua, Noble y Coronada Villa de Madrid. Historia de su antigüedad nobleza y grandeza por el licenciado Gerónimo de Quintana, Clérigo Presbítero, Notario del Santo Oficio de la Inquisición, Rector del Hospital de la Latina y natural del la misma Villa. Madrid: Imprenta del Reyno (Ed. facsímil 1954, Madrid: Artes Gráficas Municipales).

Priego, CARMEn. 1994. Museo de San Isidro. Arqueología y Tradición. Madrid: Ayuntamiento de Madrid.

RIBADENEYRA, PEDRO DE. 1688-1705. Flos Sanctorvm ó libro de las vidas de los santos escrito por el padre [.........] de la compañia de Iesvs, natural de Toledo aumentado con las vidas de mvchos santos por los padres Ivan Eusebio Nieremberg, y Francisco Garcia, todos de la compañia de Iesvus I vltimamente an añadido en esta vltima impresion con las vidas de muchos Santos para los dias vacantes en las impressiones antecedentes por el M. R. P. Fr. Andrés Lopez Guerrero del Orden de N S. Del Carmen, de la Observancia de la Provincia de Castilla, III vols. Barcelona.

Río BARREDO, MARÍA JOSÉ DEL. 1997. Fiestas públicas en Madrid (1561-1808). Madrid: Ediciones de la Universidad Autónoma de Madrid, Micropublicaciones ETD. 
RODRÍGUEZ MAÑAS, FRANCISCO. 1991. "Hombres santos y recaudadores de impuestos en el occidente musulmán, siglos VI-VIII-XII-XIV". Al Qantara XX.

SANZ MARTÍNEZ, NiCOLÁs. 1983. "El Códice de Juan Diácono", en San Isidro Labrador. Patrono de la Villa y Corte. IX Centenario de su nacimiento: 49-69. Madrid: Academia de Arte e Historia de San Dámaso. Arzobispado de Madrid Alcalá.

SIMÓN DíAz, José. 1983. "Bibliografía sobre san Isidro", en San Isidro Labrador. Patrono de la Villa y Corte. IX Centenario de su nacimiento: 31-43. Madrid: Academia de Arte e Historia de San Dámaso. Arzobispado de Madrid Alcalá.

VAUCHEZ, ANDRÉ. 1991 "Lay People's Sanctity in Western Europe: Evolution of a Pattern (twelfh and thirteenth centuries)", en Renate Blumenfeld-Kosinski and TimEA SzELL (eds.), Images of Sainthood in Medieval Europe: 21-32. Ithaca and London: Cornell University Press.

VERDÚ RuIz, MATILDE. 1986. "La ribera del Manzanares", en VV. AA. Establecimientos Tradicionales Madrileños. Cuaderno VII. El Ensanche Sur y la Ribera del Manzanares: 39-58. Madrid: Cámara de Comercio e Industria de Madrid.

VILlEGAS, AlONSO DE. 1787. Flos sanctorum vida, y bechos de Jesu-Christo, Dios, y Señor nuestro, $y$ de todos los santos de que reza la iglesia catholica. Conforme al breviario romano, reformado por Decreto del Santo concilio Tridentino. Junto con las Vidas de los Santos Proprios [sic] de España. por el M [...l, capellan de la capilla Mozarabe de la Santa Iglesia de Toledo. En esta ultima impresion se ban ordenado en un solo cuerpo por su mes, y dia proprio todos los Santos, y algunos otros. Barcelona: por la Viuda Piferrer (1. ${ }^{a}$ ed. 1775). 